\title{
Construction of regional multi-hazard interaction frameworks, with an application to Guatemala
}

\author{
Joel C. Gill ${ }^{1}$, Bruce D. Malamud ${ }^{2}$, Edy Manolo Barillas ${ }^{3}$, and Alex Guerra Noriega ${ }^{4}$ \\ ${ }^{1}$ Global Geoscience, British Geological Survey, Keyworth, NG12 5GG, UK \\ ${ }^{2}$ Department of Geography, King's College London, London, WC2B 4BG, UK \\ ${ }^{3}$ UN Office for the Coordination of Humanitarian Affairs, Guatemala City, Guatemala \\ ${ }^{4}$ Instituto Privado de Investigación sobre Cambio Climático, Guatemala City, Guatemala
}

Correspondence: Joel C. Gill (joell@ bgs.ac.uk)

Received: 29 November 2018 - Discussion started: 7 December 2018

Revised: 28 June 2019 - Accepted: 2 September 2019 - Published: 14 January 2020

\begin{abstract}
Here we present an interdisciplinary approach to developing comprehensive, systematic, and evidenced visual syntheses of potential natural-hazard interactions at regional scales (or regional interaction frameworks). Frameworks can help with understanding the multi-hazard environment of a specific spatial extent. We explain our approach and apply this in Guatemala, developing regional interaction frameworks for national and sub-national (southern Guatemalan Highlands) spatial extents. The frameworks are constructed and populated using five evidence types relevant to natural-hazard interactions: (A) internationally accessible literature (93 peer-reviewed and 76 grey-literature sources), (B) locally accessible civil-protection bulletins (267 bulletins from 11 June to 15 October 2010), (C) field observations, (D) stakeholder interviews (19 semi-structured interviews), and (E) a stakeholder workshop (16 participants). These five evidence types were synthesised to determine an appropriate natural-hazard classification scheme for Guatemala, with 6 natural-hazard groups, 19 hazard types, and 37 hazard subtypes. For a national spatial extent in Guatemala, we proceed to construct and populate a regional interaction framework (matrix form), identifying 50 possible interactions between 19 hazard types. For a sub-national spatial extent (southern Guatemalan Highlands), we construct and populate a regional interaction framework (matrix form), identifying 114 possible interactions between 33 hazard sub-types relevant in the southern Guatemalan Highlands. We also use this evidence to explore networks of multi-hazard interactions (cascades) and anthropogenic processes that can trigger natural hazards. We present this information through accessi-
\end{abstract}

ble visualisations to improve understanding of multi-hazard interactions in Guatemala. We believe that our regional interaction framework's approach to multi-hazards is scalable, working at global to local scales with differing resolutions of information. Our approach can also be replicated in other geographical settings. We demonstrate how regional interaction frameworks and the discussion of potential scenarios arising from them can help with enhancing the cross-institutional dialogue on multi-hazard interactions and their likelihood and potential impacts. We review future research directions and steps to embed interaction frameworks into agencies contributing to the implementation of the Sendai Framework for Disaster Risk Reduction.

\section{Introduction}

The Sendai Framework for Disaster Risk Reduction (UNDRR, 2015) is a global plan to reduce disaster losses from natural hazards, adopted by UN member states in 2015 . The Sendai Framework emphasises the need for multi-hazard approaches, defined as "the selection of multiple major hazards that the country faces, and the specific contexts where hazardous events may occur simultaneously, cascadingly, or cumulatively over time, and taking into account the potential interrelated effects" (UNDRR, 2017). A key, but complex, step in understanding risk (Sendai Framework, Priority for Action 1), and the focus of our paper, is understanding the multi-hazard landscape of a region (i.e. the relevant single natural hazards and the processes by which they may interre- 
late to generate combinations or cascades of hazards). In this Introduction, we give a brief background of natural-hazard interrelationships, existing regional studies of potential hazard interactions, and the general organisation of our paper.

We divide natural-hazard interrelationships into the following two categories (see Gill and Malamud, 2014; Duncan et al., 2016; Ciurean et al., 2018; Tilloy et al., 2019, for a general review of hazard interrelationship frameworks):

- Compound (or coincident) hazards. These are where two or more independent hazards impact the same region in time and/or space (e.g. a heat wave at the same time as an earthquake).

- Concurrent or consecutive hazards. These are where two or more hazards (either dependent or independent) occur successively and cause cumulative pressures on a given region (e.g. a hurricane occurring a few days after an earthquake or an earthquake triggering many landslides). Dependent hazards may involve two types of hazard interaction.

a. Triggering interactions. These are where one hazard triggers another hazard (e.g. an earthquake triggering a landslide).

b. Increased probability interactions. These are where one hazard increases the probability of another hazard occurring (e.g. a wildfire increasing the probability of debris flows given heavy rain).

These interrelationships can combine to form complex networks (with both spatial and temporal dimensions). For example, tropical storms can trigger floods and/or landslides, volcanic eruptions can trigger wildfires that subsequently increase the probability of debris flows, and earthquakes can trigger regional subsidence which increases the likelihood of flooding. Many more examples, and extensive case studies, of such interactions feature in the literature (e.g. Tarvainen et al., 2006; Kappes et al., 2010; Gill and Malamud, 2014; Duncan et al., 2016; Tilloy et al., 2019).

Stakeholders involved in implementing the Sendai Framework (e.g. civil-protection agencies, hazard-monitoring scientists, urban planners, and development practitioners) will therefore all benefit from resources (e.g. tools and review reports) that help with increasing understanding of the multihazard landscape of a region by systematically identifying and characterising potential hazards and hazard interactions. Building on global approaches for identifying and characterising hazard triggering and increased probability interactions laid out in Gill and Malamud (2014, 2016, 2017) and Tilloy et al. (2019), here we explore the following research questions:

- For a defined spatial region, how does one construct and populate a synthesis of potential natural-hazard interactions using blended sources of evidence for past case histories and theoretical future possibilities from that region's characteristics? (Here we focus particularly on triggering and increased probability interactions but discuss additional hazard interrelationships in the context of future developments of this work.)

- How do triggering interactions documented in the literature contrast with the knowledge of hazard or civilprotection professionals operating in the region?

- What are the implications of our multi-hazard methodologies on supporting disaster risk reduction, management, and response?

We address these questions by collating and uniting diverse evidence sources (e.g. field observations and interviews) from the natural and social sciences through a visual database (i.e. a matrix) of potential hazard interactions at regional (e.g. national and sub-national) scales. We demonstrate an approach that is comprehensive (includes a broad array of potential hazards), systematic (exploring the potential for interactions between each hazard pairing), and evidenced (documenting the evidence for the existence of interactions). We label these frameworks "regional interaction frameworks" defined as visualisations that support the identification and characterisation of relevant hazard interactions in a defined region (from $10^{2}$ to $10^{6} \mathrm{~km}^{2}$ ).

Currently, regional studies of potential hazard interactions are sparse and typically do not explain a replicable and scalable method for systematically doing this. Table 1 outlines and characterises seven examples of frameworks for specific named regions or geographical features that include natural hazards and a deliberate attempt to characterise possible hazard interactions. While there is significant variation in the approaches used to construct and populate these frameworks, they helpfully demonstrate the scalability of regional interaction frameworks and issues to be considered when constructing regional interaction frameworks. These examples also highlight the complexity of understanding potential hazard interactions. For example, while many multi-hazard studies focus only on two or three hazards (Ciurean et al., 2018), the examples in Table 1 all show regions exposed to many more hazard types (6-11 natural hazards). This results in significant complexity when trying to constrain and characterise the potential interactions between natural hazards, using either qualitative or quantitative tools.

Building on these examples, we present and apply an interdisciplinary methodology in this paper to develop and enhance comprehensive, systematic, and evidenced regional interaction frameworks. We apply this interdisciplinary approach in the context of Guatemala to produce a suite of comprehensive and robust frameworks of potential hazard interactions for two spatial extents (national and sub-national) and describe their application to multi-hazard disaster risk reduction in Guatemala. We trialled our approach in Guatemala due to (i) the hazardousness of the region and (ii) logis- 
Table 1. Examples of seven regional interaction frameworks, including a summary of the spatial extent, hazards and processes considered, and interaction types.

\begin{tabular}{|c|c|}
\hline Authors & $\begin{array}{l}\text { Summary } \\
\text { (spatial extent, hazards and processes considered, and interaction types) }\end{array}$ \\
\hline $\begin{array}{l}\text { Tarvainen et } \\
\text { al. (2006) }\end{array}$ & $\begin{array}{l}\text { - Continental spatial extent (Europe). } \\
\text { - Binary matrix. } \\
\text { - Identifies interactions between } 11 \text { natural hazards (avalanche, drought, earthquake, extreme } \\
\text { temperature, flood, forest fire, landslide, storm surge, tsunami, volcanic eruption, and winter storm) and } 4 \\
\text { technological hazards (air traffic accident; chemical plant; nuclear power plant; and oil processing, transport, and } \\
\text { storage). } \\
\text { - Interactions are determined based on physical processes (causal correlation) and are only considered when } \\
\text { hazard intensities in a given region exceed an average value. }\end{array}$ \\
\hline $\begin{array}{l}\text { De Pippo et } \\
\text { al. (2008) }\end{array}$ & $\begin{array}{l}\text { - Sub-national spatial extent (northern Campanian coast, Italy). } \\
\text { - Descriptive matrix is used to characterise interactions between hazards, which are weighted according to } \\
\text { their importance in different zones along the coast. } \\
\text { - Semi-quantitative method to quantify, rank, and map the distribution of hazard. } \\
\text { - Considers the effect of six hazards (shoreline erosion, riverine flooding, surge, landslide, seismicity, } \\
\text { and volcanism) and the effect of manufactured structures. }\end{array}$ \\
\hline $\begin{array}{l}\text { Kappes et al. } \\
(2010)\end{array}$ & $\begin{array}{l}\text { - Sub-national spatial extent (French Alpine region of Barcelonnette). } \\
\text { - Uses a combination of binary and descriptive matrices. } \\
\text { - Considers both triggering interactions and interactions where a hazard changes the disposition or } \\
\text { general setting that favours another hazard process. } \\
\text { - Seven primary natural hazards (avalanche, debris flow, rockfall, landslide, flood, heavy rainfall, and } \\
\text { earthquake). }\end{array}$ \\
\hline $\begin{array}{l}\text { van Westen } \\
\text { et al. (2014) }\end{array}$ & $\begin{array}{l}\text { - Sub-national (European mountainous environments). } \\
\text { - Possible interactions are mapped out using a network flow diagram, including interactions between the } \\
\text { seven resulting secondary hazards. Considers two primary triggers (earthquake and meteorological extreme) } \\
\text { and seven resulting hazards or processes (mass movement, snow avalanche, forest fire, land degradation, } \\
\text { flooding, seiche, and technological hazard). }\end{array}$ \\
\hline $\begin{array}{l}\text { Neri et al. } \\
(2008)\end{array}$ & $\begin{array}{l}\text { - Sub-national (Vesuvius volcano, Italy). } \\
\text { - Uses a quantitative (probabilistic) approach to map out possible future eruptive scenarios. } \\
\text { - Scenarios consider } 10 \text { hazards (volcanic eruption, fallout, ballistics, pyroclastic density current, debris } \\
\text { avalanche, tsunami, flood, landslide, lahar, mudslide, and heavy rain). }\end{array}$ \\
\hline $\begin{array}{l}\text { Neri et al. } \\
(2013)\end{array}$ & $\begin{array}{l}\text { - Sub-national (Kanlaon volcano, Philippines). } \\
\text { - Presented using an event or scenario tree. } \\
\text { - Uses a semi-quantitative method, combing geological and historical data to consider hazard events. } \\
\text { - Seven hazards considered (volcanic eruption fallout, volcanic eruption ballistics, pyroclastic density current, debris } \\
\text { avalanche, tsunami, flood, and lahar or mudslide). }\end{array}$ \\
\hline $\begin{array}{l}\text { Liu et al. } \\
(2016)\end{array}$ & $\begin{array}{l}\text { - Sub-national (Yangtze River Delta, China). } \\
\text { - Zones of similar hazards and hazard interactions are identified and spatially mapped. } \\
\text { - Hazard interactions classification is based on "the hazard-forming environment", defined as the } \\
\text { geophysical environment that natural hazards arise from. } \\
\text { - Four interaction types are considered. } \\
\text { - } 10 \text { natural hazards (earthquake, volcanic eruption, tropical cyclone, slow riverine flood, fast riverine } \\
\text { flood, coastal flood, pluvial flood, landslide, avalanche, and drought), with a selection of these being relevant to } \\
\text { the Yangtze River Delta case study. }\end{array}$ \\
\hline
\end{tabular}

tical feasibility (contacts, language, and accessibility). A broad range of natural hazards and anthropogenic processes in Guatemala make it an appropriate country for examining hazard interactions. Guatemala's dynamic geological history and geographical setting give rise to many potential hazards.
These include geological (e.g. earthquakes, volcanic activity, landslides, and surface collapses) and hydrometeorological hazards (e.g. tropical cyclones, thunderstorms, hailstorms, tornados, coastal storm surges, floods, drought, heatwaves, and cold spells), as defined by UNDRR (2017). Guatemala 


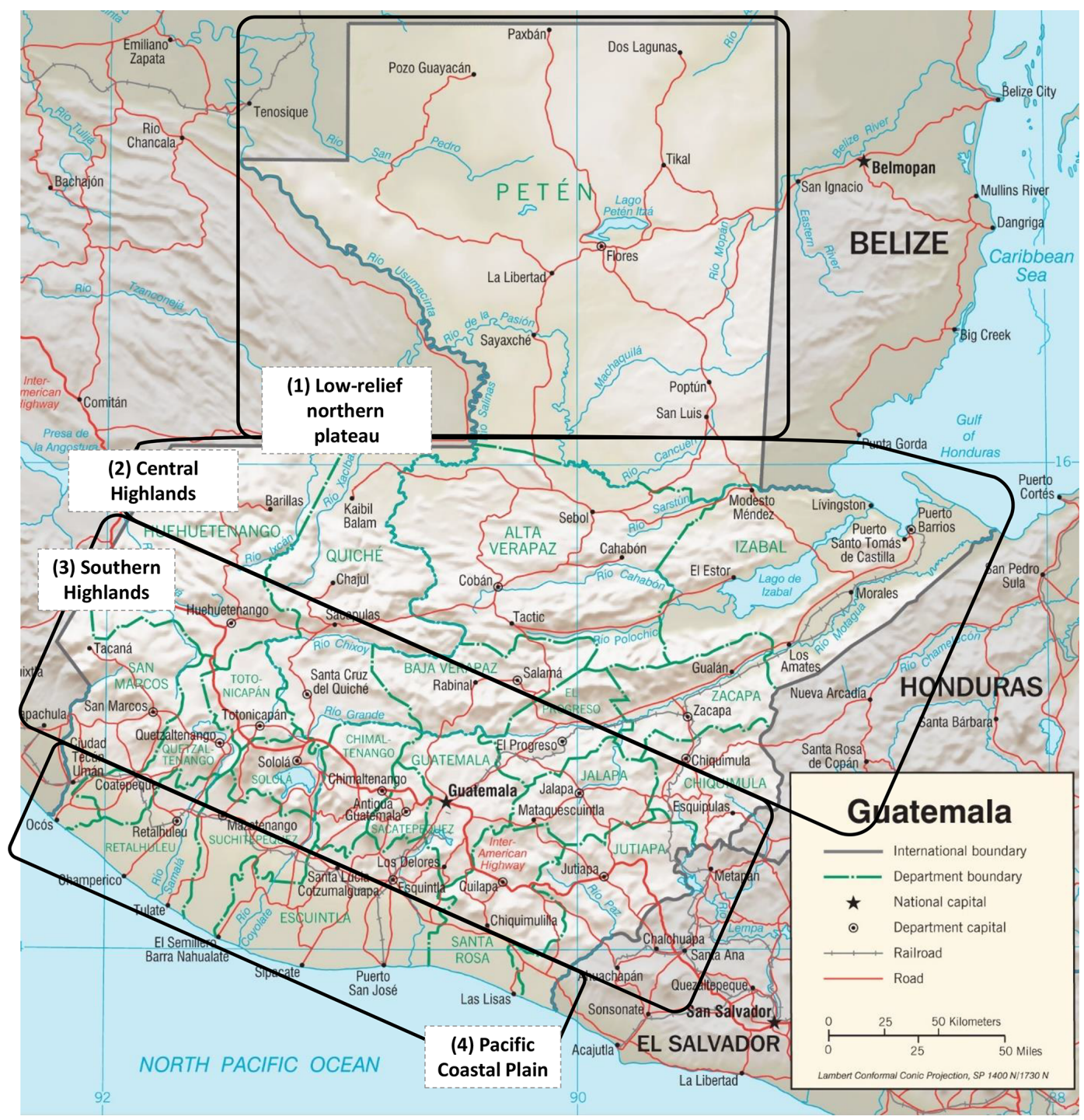

Figure 1. Guatemala map: key locations and physiography, using CIA (2001) Base 802723AI (C00113) 12-00. A combined political and physiographic map of Guatemala, showing differential relief (greyscale shading), departmental boundaries (green lines and text), key locations (black text), rivers (blue lines and text), and roads (red lines). We group Guatemala into four broad regions (1-4) based on physiography. We refer particularly to the southern Guatemalan Highlands (region 3) throughout this paper.

ranks high in descriptions of countries exposed to multiple hazards and risks (e.g. Welle et al., 2013; Kreft et al., 2015; Bündnis Entwicklung Hilft/United Nations University, 2017). Figure 1 shows a map of Guatemala, including key locations and four physiographic regions that we have defined and refer to later in the paper.

We believe this paper to be the first national-scale comprehensive characterisation of potential hazard interactions in the peer-reviewed literature, relevant to a wide range of actors involved in disaster risk reduction (DRR). While the regional interaction frameworks developed in this paper specifically support Guatemalan stakeholders, we suggest that our approach is replicable and can support implementation of the Sendai Framework in other settings through improved characterisation of multi-hazard interactions, as we discuss throughout this paper.

The paper is structured as follows: in Sect. 2 we outline the methods used to collect five diverse evidence types, characterise this evidence, and describe how we integrate this evidence to construct and populate a regional interaction framework. We combine our description of data collection methods with the characterisation of the data, as it is more helpful for the reader to have these together. In Sect. 3 we integrate and use this evidence to characterise hazard interactions and networks of interactions (cascades), constructing two regional interaction frameworks for Guatemala (national and sub-national spatial extents). In Sect. 4 we discuss future developments of this work and our findings in the context 
Table 2. Examples of five diverse evidence categories with examples for each one that might indicate the relevance of a given multi-hazard interaction. We use an asterisk $\left(^{*}\right)$ to indicate the examples of evidence that are used in this paper (grouped into evidence types A to E; see Sect. 2.1).

\begin{tabular}{|c|c|}
\hline Evidence category & Examples \\
\hline 1. Publications and reports & $\begin{array}{l}\text { - Peer-reviewed and other research publications* (Type A) } \\
\text { - Public and confidential government, technical, private sector, and/or civil-society reports* (Types A and B) } \\
\text { - Maps and archive documents* (Type A) } \\
\text { - Student projects (e.g. dissertations and theses)* (Type A) } \\
\text { - Books* (Type A) } \\
\text { - Diaries }\end{array}$ \\
\hline 2. Social and other media & $\begin{array}{l}\text { - Photographs and video clips (e.g. from print and online newspapers, blogs, websites, tweets, } \\
\text { and citizen science)* (Type A) } \\
\text { - Newspaper articles* (Type A) } \\
\text { - Social-media posts (e.g. "tweets") }\end{array}$ \\
\hline 3. Field evidence & $\begin{array}{l}\text { - Observations from the impact on the built environment (e.g. marks on vertical services to } \\
\text { indicate flooding occurred or the minimum extent flood water reached) } \\
\text { - Geological mapping and any field identification of evidence of the hazard occurring (e.g. flood } \\
\text { deposits)* (Type C) }\end{array}$ \\
\hline 4. Stakeholder engagement & $\begin{array}{l}\text { - Interviews with the public, hazard professionals, and civil-protection officials* (Type D) } \\
\text { - Focus groups } \\
\text { - Workshops* (Type E) }\end{array}$ \\
\hline 5. Miscellaneous & $\begin{array}{l}\text { - Insurance records } \\
\text { - Instrumental records and associated notes } \\
\text { - Emergency call-out and incident records from emergency services } \\
\text { - Remote-sensing images }\end{array}$ \\
\hline
\end{tabular}

of regional interaction frameworks and multi-hazard assessments for disaster risk reduction. Conclusions are presented in Sect. 5.

\section{Data and methods used to construct the regional interaction framework}

\subsection{Evidence types and integration}

Developing comprehensive and evidenced regional interaction frameworks requires diverse evidence to improve the systematic identification of relevant hazards and interactions. From our experience, in Table 2, we outline examples of different types of evidence to help construct and populate regional interaction frameworks and group these into five categories: (1) publications and other reports, (2) social and other media, (3) field evidence, (4) stakeholder engagement, and (5) miscellaneous. Some overlap exists between these categories, and not all the examples given are relevant in any given location.

In this paper, we use many of the examples of evidence in Table 2 to help construct and populate a regional interaction framework for Guatemala. We group our evidence into five broad types (A-E below) and use these five types throughout this paper.
A. International literature (publications and reports). This is a comprehensive synthesis of literature describing natural hazards in Guatemala and their interactions. This combines examples of both (1) publications and other reports and (2) social and other media, from Table 2 , including peer-reviewed material, technical reports, databases, and media reports (93 peer-reviewed and 76 grey literature sources; Sect. 2.2).

B. Civil-protection bulletins (locally accessible publications and reports). Analysis of government-issued, Spanish-language civil-protection information bulletins (267 bulletins from 11 June to 15 October 2010; Sect. 2.3).

C. Field observations. These are reconnaissance trips, giving an overview of the hazard landscape of Guatemala (three sites discussed in the text; Sect. 2.4).

D. Stakeholder interviews. These are semi-structured interviews with hazard and civil-protection professionals in Guatemala (19 interviews, conducted from 28 February to 14 March 2014; Sect. 2.5).

E. Workshop. This is a $3 \mathrm{~h}$ workshop with hazard and civilprotection professionals in Guatemala (16 participants, 6 March 2014; Sect. 2.6). 
For the latter two evidence types (D and E), principal government organisations tasked with informing disaster risk reduction and response activities in Guatemala are CONRED (2018a; Coordinadora Nacional para la Reducción de Desastres - National Coordinator for Disaster Reduction) and INSIVUMEH (2018; Instituto Nacional de Sismología, Vulcanología, Meteorología e Hidrología - National Institute for Seismology, Volcanology, Meteorology and Hydrology). CONRED focuses on disaster preparedness and response, with a broad range of professional expertise. INSIVUMEH focuses on hazard monitoring and is a scientific agency of the government of Guatemala. Additional organisations include universities (e.g. Universidad de San Carlos de Guatemala), private-sector consultancies and research institutes (e.g. Private Institute for Climate Change Research), civil-society organisations (e.g. Oxfam), and regional and international intergovernmental organisations (e.g. CEPREDENAC or UN OCHA).

Other evidence types (e.g. historical records or community knowledge) are included in the peer-reviewed and greyliterature publications we examined or may be particularly pertinent in other geographical locations. The use of multiple evidence types (vs. a reliance on one evidence type) facilitates a more comprehensive characterisation of hazards and hazard interactions. For each evidence type considered, we do not use all possible examples, methods, and sources; rather we use examples of key case studies from regions of interest. Collecting and interpreting this evidence requires engagement with a range of organisations engaged in research and practitioner work relating to natural hazards, disaster risk reduction, and disaster response. In Sect. 2.2 to 2.6 we characterise our data (evidence types) and the methods used to collect and unite this to address our research questions. We outline limitations associated with this evidence and the methods used to collect it in Sect. 2.7. In Sect. 2.8, we summarise how we integrate evidence types to develop our regional interaction frameworks in Sect. 3.

\subsection{Publications and reports (internationally accessible; evidence type $A$ )}

Internationally accessible publications and reports includes both peer-reviewed and grey literature, such as journal articles, edited volumes, master's and $\mathrm{PhD}$ theses, textbooks, technical reports, databases, and NGO disaster situation reports. This compilation of literature includes reports on hazard events in specific geographic regions, providing evidence of hazard interactions. For example, Rose et al. (2004) presents an edited volume of papers on natural hazards in El Salvador, and ReliefWeb (2018) presents a disaster situation report on the impact of Tropical Storm Nate in Central America. We identified multiple publication and report types with information about Guatemala. We prioritised literature giving a broad overview of natural hazards, synthesising multiple texts, or characterising hazard interactions. It is beyond the scope of this study to examine publications on every aspect of hazards in Guatemala or to review all publications on any one aspect of a hazard.

We primarily accessed literature using large Web databases (Google Scholar and Web of Science) for peerreviewed articles and general online searches for other grey literature (e.g. media reports). We used Boolean search methods, including both "Guatemala" and keywords associated with a preliminary list of 21 natural hazards (from Gill and Malamud, 2014). For example, "earthquake", "aftershock", "seismic", "tremor", and "liquefaction" were searched for alongside "Guatemala" and "Central America" to identify relevant material. We evaluated results to determine their relevance and identify other keywords. We also identified specialist books, such as an edited volume on the geology of Central America (Bundschuh and Alvarado, 2007).

We examined literature in a systematic manner, collating references, maps, and figures for 17 (of the 21) natural hazards: earthquake, tsunami, volcanic eruption, landslide, flood, drought, regional subsidence, ground collapse, soil (local) subsidence, ground heave, storm, tornado, hailstorm, lightning, extreme temperature (heat), extreme temperature (cold), and wildfire. Snow avalanche and snowstorm have limited spatial relevance to Guatemala, and geomagnetic storm and impact event have little country-specific (vs. generically relevant) information. For each hazard considered, we cross-referenced diverse literature to characterise it at a level of detail appropriate to this study, including information on spatial and temporal distribution, triggering relationships, and impacts. We identified and used 169 sources as evidence, with $93(55 \%)$ of these being peer-reviewed and $76(45 \%)$ of these being grey literature.

\subsection{Publications and reports (locally accessible; evidence type $B$ )}

Another evidence type to inform the development of regional interaction frameworks is locally accessible reports, such as government or NGO bulletins, newspapers, and emergency call-out records. Civil-protection information bulletins and newspapers can both give a focused overview of naturalhazard occurrences (e.g. Guzzetti et al., 1994; Trimble, 2008; Raška et al., 2014; Taylor et al., 2015), providing information on hazard interactions or noting triggering relationships.

In Guatemala, we use Spanish-language civil-protection information bulletins from the CONRED. Bulletins are issued when there is a threat to lives, livelihoods, and infrastructure and include information on hazards, their spatial and temporal extent, and their impacts, including triggering other hazards. Natural hazards occurring in remote regions or having a very low impact (e.g. very small landslides) are unlikely to be included in bulletins, and therefore bulletins do not provide a complete record of events. CONRED may issue multiple bulletins per day, depending on the evolution of, for example, a weather system or a disaster event. Bulletins 
are distributed to a mailing list of personnel, with some on their website (CONRED, 2018b) and ReliefWeb (2016). At the time of writing, CONRED bulletins were not systematically archived online. We therefore classify these bulletins as locally accessible.

CONRED made 291 information bulletins available to the authors (electronic format), published over a $127 \mathrm{~d}$ period between the 11 June and 15 October 2010, of which 24 were corrupt files and 267 were accessible. Based on their numbering, we believe that CONRED published 413 bulletins during this $127 \mathrm{~d}$ period. Additional information that characterises these bulletins is included in the Supplement (Table S1). We searched the 267 accessible bulletins for keywords, placing these into context by looking at the surrounding sentences. Taylor et al. (2015) used this approach to enrich the UK national landslide database by examining newspaper archives.

We selected and used the following six keyword verbs connecting two hazard types and suggesting an interaction between them (with an abbreviated Spanish verb base in parentheses): to trigger (desenca), to provoke (provoc), to generate (genera), to cause (caus), to produce (produ), and to catalyse (catal). We performed a keyword Boolean search in Spanish using the abbreviated form of the verb base to ensure the return of multiple derivatives of the verb. To check if there were other verbs of interest, we then searched for the following hazard keywords in Spanish form (both singular and plural): seismic, earthquake, volcano, eruption, landslide, flood, collapse, sinkhole, hurricane, storm, tsunami, drought, tornado, wind, and rain. We also searched for references to three active volcanoes (Pacaya, Santiaguito, and Fuego) in Guatemala. From these hazard keywords and three volcanoes, we looked for any further interaction verbs that might be included near these words and identified no additional keyword verbs. The number of keyword search results for each of the six keyword abbreviated verb bases connecting two hazard types are as follows: to trigger (desenca; 0 results), to provoke (provoc; 26 results), to generate (genera; 58 results), to cause (caus; 22 results), to produce (produ; 37 results), and to catalyse (catál; 0 results). In some cases, the same bulletin had more than one result.

In total, there were 143 results from 95 CONRED bulletins prior to us processing them based on their relevance to the theme of hazard interactions. By examining the context, we determined that 39 of the 143 results (from 36 different bulletins on 28 unique days) described unique events where interactions occurred between natural hazards. These results are presented in Table S2. The results in this section, although based on an incomplete dataset, demonstrate examples of the range of types of interactions that could occur. Further research could use a larger sample of bulletins to better characterise interactions in Guatemala or an event database such as EM-DAT (CRED, 2018). This would be necessary if the frequency of different types of events were a consideration, with a 4-month period being too short to analyse this.

\subsection{Field observations (evidence type C)}

Field observations can also help with understanding the relevance and dynamics of hazards and hazard interactions. For example, Havenith et al. (2003) describe field evidence of earthquake-triggered landslides in the northern Tien Shan of Kyrgyzstan. Approaches include reconnaissance visits to improve contextual understanding of the region; detailed geological, geomorphological or hazard mapping; and the application of technologies such as rain gauges, drones, and thermal-imaging infrared cameras.

In Guatemala, from January to March in 2014 (9 weeks total), the lead author visited regions in the southern Guatemalan Highlands (identified in Fig. 1) affected by multiple natural hazards and anthropogenic activity. This helped with familiarising the non-Guatemalan authors with the features of key locations and hazards in Guatemala, but primary field data (e.g. community interviews) were not gathered. Observing the spatial and temporal scales at which hazards and anthropogenic processes act enhanced understanding of Guatemala's multi-hazard environment. It also enriched interviews with expert participants (described in Sect. 2.5), with the interviewer making better use of examples, local places names, and descriptors used by participants to characterise and evidence natural-hazard interactions in Guatemala.

The lead author conducted multiple field visits alongside INSIVUMEH, with support from the University of Bristol, and one field visit with CONRED. This helped with developing constructive relationships, establishing the mutual trust and respect required for subsequent data-rich interviews (Kitchin and Tate, 2000). Examples of principal field locations and relevant interactions are (i) Lake Atitlán (e.g. tropical storms triggering landslides, landslides triggering flooding, and landslides triggering lake tsunamis), (ii) Fuego volcano (e.g. lahars triggering floods), and (iii) Santiaguito volcano (lahars triggering flooding).

\subsection{Stakeholder engagement: interviews (evidence type D)}

Interviews provide additional evidence to construct and populate regional interaction frameworks. Participants often come from diverse backgrounds, with differing understanding of natural hazards and geographic regions. Participants with relevant evidence can include hazard and disaster professionals and local people who might be impacted by hazards (e.g. farmers, local government, and communities). Selecting participants based on their experience and relevance to a research question (purposeful sampling) can result in data-rich interviews (MacDougall and Fudge, 2001; Longhurst, 2003; Suri, 2011; Palinkas et al., 2015). Semistructured interviews provide one means by which to have this dialogue, with questions focused on hazards and hazard interactions. This style gives enhanced freedom in exploring 
areas of interest and pursuing emerging lines of enquiry $(\mathrm{Qu}$ and Dumay, 2011).

Prior to stakeholder engagement in Guatemala in 2014, we obtained ethics approval (reference REP(GSSHM)/12/1318) from King's College London for research with human participants. At the start of each interview (conducted by the authors Joel C. Gill or Joel C. Gill and Bruce D. Malamud) we explained the purpose of our work and sought informed, prior consent to use data generated. All participants gave permission for us to use their data and identify their institution unless this would identify the individual. We interviewed 21 hazard and civil-protection professionals in Guatemala during 19 interviews. Table S3 characterises the interview participants. Participants came from academia, the private sector, INSIVUMEH, and CONRED. We selected interview participants from diverse professional backgrounds in terms of hazard speciality (e.g. earthquakes, landslides, and floods) and engagement in the disaster cycle (e.g. early warning, mitigation, and recovery). We identified contacts before travelling to Guatemala through their online profiles and professional engagement in other projects and through introductions once in Guatemala.

Interviews ranged from 30 to $120 \mathrm{~min}$, following a semistructured approach (Longhurst, 2003; Qu and Dumay, 2011). Interviews included opportunities for participants to talk about (i) their background and training, (ii) their consideration and use of information on hazard interactions, (iii) examples of existing networks of multi-hazard interactions, and (iv) hazard interaction visualisations. All interviews aimed to cover these key themes; however there were differences in the order in which they were introduced and the specific questions asked. Interviews were conducted in Spanish (with a translator), in Spanish (without a translator), and in English, depending on the context. To reduce possible power relations, we ensured that participants were at ease with the interviewer and participant setting (Kitchin and Tate, 2000; DiCicco-Bloom and Crabtree, 2006; Qu and Dumay, 2011).

Table S4 presents key statements relating to natural hazards, hazard interactions, and anthropogenic processes, extracted from these 19 semi-structured interviews. Multiple participants highlighted specific interaction examples. These include ones already noted in accessible peer-reviewed or grey-literature sources (e.g. lahars from Santiaguito triggering flooding; Harris et al., 2006) and interactions not described in other evidence types (e.g. Pacific coastal flooding due to simultaneous high tides and river sedimentation).

\subsection{Stakeholder engagement: workshop (evidence type E)}

Workshops are another form of stakeholder engagement and are designed to generate data through activities and focused discussion. We organised a $3 \mathrm{~h}$ workshop in Guatemala involving 16 civil-protection professionals at CONRED. Participants included senior and junior staff working in diverse departments. Table S3 characterises the 16 workshop participants (of whom 4 also took part in interviews), with all giving permission for us to use their data in an anonymised form. During our workshop, participants independently completed two tasks.

1. Task 1: network linkage diagram for 21 natural hazards (16 participants). Participants used this to record triggering relationships that they believed to be relevant to Guatemala. We did not expect any participant to map out all relevant interactions.

2. Task 2: $7 \times 11$ natural-hazard interaction matrix (15 participants). Participants completed a blank hazard interaction matrix, with 7 primary hazards on the vertical axis and 11 secondary hazards on the horizontal axis.

We therefore collected two sets of visual records that document participants' perceptions of relevant hazard interactions in Guatemala. We include all completed diagrams in Figs. S1 and S2. Completed network linkage and interaction matrix diagrams vary in the number and range of interactions proposed to be relevant in Guatemala. The number of interactions proposed by any one participant using the hazard linkage diagram, for example, ranged from 8 to 35 , with a mean of 18 and a median (50th percentile) of 15 .

Using all 16 completed network linkage diagrams (Task 1 above), we can represent the combined knowledge of the workshop participants and use this as evidence when constructing regional interaction frameworks for Guatemala. In Fig. 2, we overlay evidence from 16 completed network linkage diagrams on a blank interaction framework, showing the number of participants (out of 16) proposing each triggering relationship. This interaction framework has 21 primary natural hazards on the vertical axis and the same 21 secondary natural hazards on the horizontal axis, using an approach laid out in Gill and Malamud (2014).

Of a total possible $441(21 \times 21)$ interactions, there are 86 different interactions proposed in Fig. 2 as being relevant in Guatemala (by 1-16 participants), equivalent to $20 \%$ of the 441 possible interactions. Consequently, 355 interactions ( $80 \%$ of the 441 possible interactions) were determined by all 16 participants as not being relevant in Guatemala. Some of the proposed interactions may not be relevant (false positives), and others not proposed by participants may be relevant (false negatives) in Guatemala. We present detailed statistics resulting from Task 1 and 2 of this workshop, and an analysis of the resultant hazard interaction matrices, in the Supplement (p. 11-16). The results of these two workshop tasks highlight different opinions on which hazard interactions are relevant in Guatemala. There is strong consensus on the occurrence of some interactions but weak consensus on others. The workshop results demonstrate the need for communication across hazard disciplines and the value 

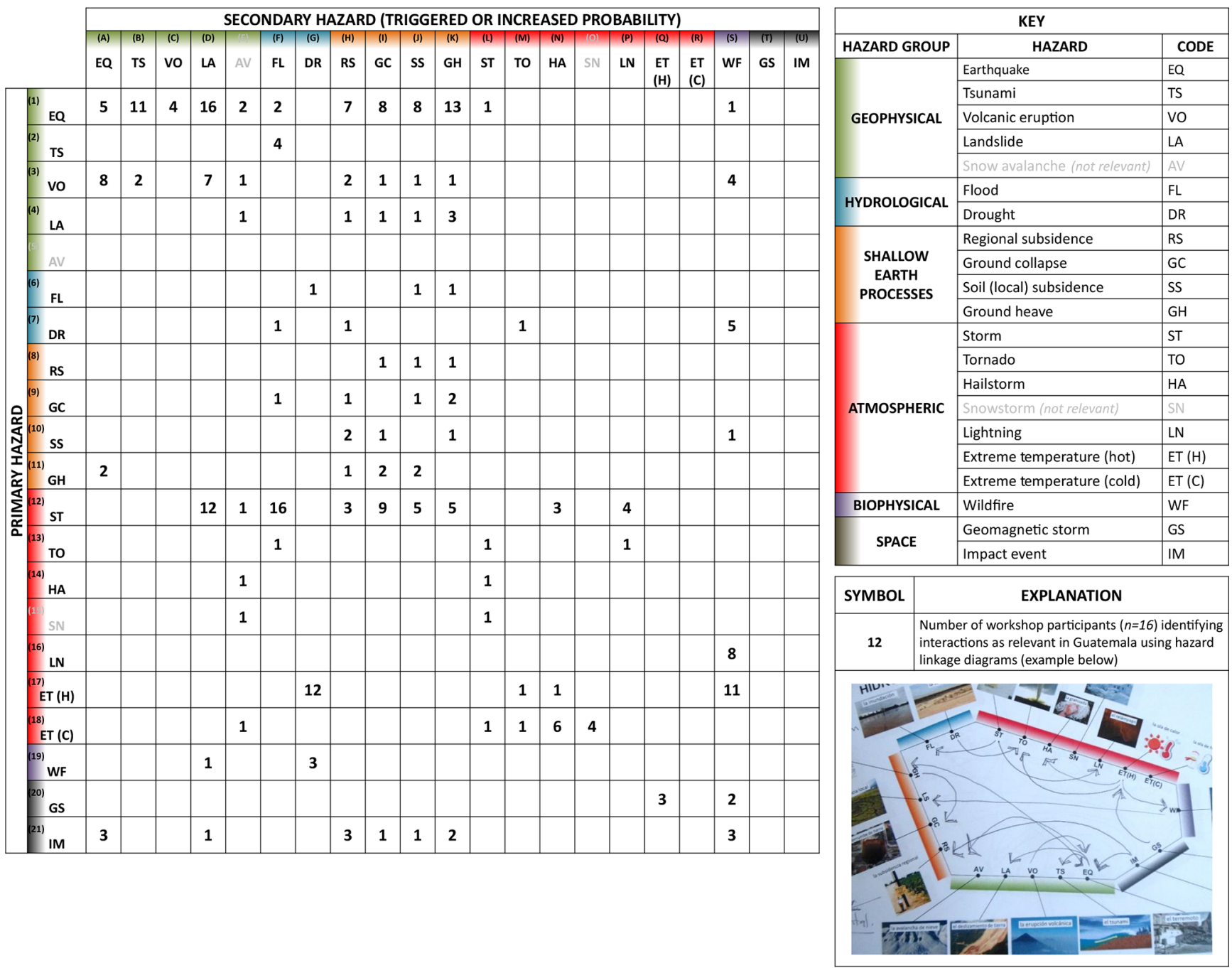

Figure 2. Stakeholder identification of possible hazard interactions in Guatemala, using network linkage diagrams produced by 16 civilprotection professionals in Guatemala. A $21 \times 21$ matrix with 21 primary natural hazards on the vertical axis and the same 21 natural hazards presented as secondary hazards on the horizontal axis. Visualisation structure based on Gill and Malamud (2014). These hazards are coded, as explained in the key. Numbers indicate the number of stakeholders (from a maximum of 16) proposing each hazard interaction as being possible in Guatemala. This information was collected using blank network linkage diagrams for 21 hazards during a workshop in Guatemala on 6 March 2014. The workshop is described in Sect. 2.6, and all images from the workshop are included in Figs. S1 and S2.

of comprehensive, systematic, and evidenced frameworks to enhance understanding of relevant interactions.

\subsection{Limitations associated with methods and data collection}

Evidence types A-E, characterised in Sect. 2, are each associated with limitations and uncertainties.

i. Information accuracy. Based on working with blended sources of grey-literature evidence, we found that it can sometimes be difficult to verify information sources, including media articles and textbooks, civil-protection bulletins, and personal perspectives offered through interviews and workshops. Where possible, we evaluated authenticity by cross-referencing grey and older literature with peer-reviewed and recent literature. Including grey-literature, however, broadens the scope of reviews and provides comprehensive access to available published evidence (Mahood et al., 2014).

ii. Bias towards high-impact events. Civil-protection bulletins, like newspaper articles, focus on events that affect the things humans value (Carrara et al., 2003) and thus exclude events with a low societal impact. In contrast to newspaper records, bulletins are less likely to focus on novel events (Moeller, 2006), and it is reasonable to expect a higher level of specialist understanding 
compared to newspaper journalists (Ibsen and Brunsden, 1996).

iii. Information omission. Our semi-structured approach to interviews may make it difficult to focus on important issues (Kitchin and Tate, 2000), increasing the likelihood of missing pertinent topics.

iv. Language barriers. The evidence in Sect. 2 required the two non-Guatemalan authors to work across language barriers. Civil-protection bulletins required translation from English to Spanish (when selecting keywords) and Spanish to English (when analysing keyword search results). We did not translate all the text in the 677 pages of the bulletins but rather searched for keywords within the text and examined their context. Working in a nonnative language may have resulted in missing interactions and/or misunderstanding context. Interviews and the workshop were conducted in a non-native language (either for us or the interviewee), making it harder to ensure consistency and minimise the omission of information (Squires, 2009). The use of translators may also result in challenges (Temple and Edwards, 2002; Temple and Young, 2004). For example, translators can change the meaning of questions, directly or indirectly contribute to answers, or change interview dynamics. Careful selection of translators can minimise the impact of these limitations, as can working with researchers with an appropriate level of Spanish.

v. Cultural barriers and positionality. Interviews and the workshop involved working across cultures. Our position in social and cultural structures influences our perspective of the world and the way in which this then influences the conduct and interpretation of stakeholder engagement (e.g. Merriam et al., 2001; Sultana, 2007; Fisher, 2015). Race, nationality, age, gender, and social and economic status influence our positionality (Madge, 1993), as do prior experiences pertinent to this research. The interviewer, translator, and interviewees may have different perspectives, value systems, customs, and social behaviours. Relationships between these groups can be complex and dynamic, with similarities and differences (Merriam et al., 2001). Recognising cultural differences and similarities has implications on how to manage interview contexts to ensure that they are fruitful (Schneider and Barsoux, 2002).

vi. Participant selection. Hosts at CONRED and INSIVUMEH generally selected interview and workshop participants. We desired participants from a diversity of professional backgrounds and levels of seniority, and this was generally respected. While participant selection was not in our control, the purposeful sampling used was an appropriate approach (MacDougall and Fudge, 2001; Longhurst, 2003; Suri, 2011; Palinkas et al., 2015). vii. Power dynamics. Age, gender, educational level, ethnicity, and socio-economic status can influence an interview or workshop process and the results (e.g. Valentine, 1997; Edwards, 1998; Kitchin and Tate, 2000; Qu and Dumay, 2011). Genuine rapport, respect, trust, and an understanding of cultural differences can reduce the impact of power dynamics (Kitchin and Tate, 2000; DiCicco-Bloom and Crabtree, 2006).

viii. Peer influence. During the workshop, a controlled environment was encouraged during the completion of tasks. It was, however, difficult to prevent those sitting next to each other from seeing other contributions and speaking about what they were including.

ix. Hazards and interaction classifications. Gill and Malamud (2016) discussed difficulties in distinguishing between triggering and increased probability interaction types for natural hazards. Workshop participants may have found this distinction between two different interaction types confusing, inadvertently characterising an interaction as one type when they meant the other. Participants may have a different understanding of what any of the interaction or hazard types includes, and the use of a predefined hazard scheme in workshops may restrict discussion of other hazards not included in this scheme.

These factors are likely to have resulted in some uncertainties within the evidence used and therefore within the interaction frameworks produced using this evidence. Some sources of uncertainty can be mitigated, and appropriate actions were taken to do so, including the following:

- using a reflexive and respectful approach reduced language barriers, cultural barriers, and power dynamics on the results of stakeholder engagement;

- using a critical approach to literature analysis determined where inaccuracies may exist in grey or historical literature;

- integrating multiple evidence types to reduce the impact of uncertainties on regional interaction frameworks;

- cross-referencing personal perspectives expressed in interviews, for example, with peer-reviewed literature to explore accuracy;

- using global interaction frameworks to serve as useful databases of what could occur, helping to evaluate the scope of possible interactions before ascertaining their relevance to Guatemala.

We suggest, therefore, that the regional interaction frameworks presented in the remainder of this paper are robust assessments of potential triggering and increased probability interactions in Guatemala. It is possible, however, that relevant hazard interactions and anthropogenic processes, or the likelihood or spatial distribution of these, will vary over time. 


\subsection{Integration of evidence types to construct and populate interaction frameworks}

The construction of comprehensive and systematic regional interaction frameworks requires three components for a region of interest, each bringing together diverse strands of evidence and unifying them within a formal structure, supported by expert knowledge (Neri et al., 2008):

i. information on relevant single hazards and appropriate ways to classify these, using the evidence in Sect. 2.2 to 2.6 and the classification of 21 natural hazards in Gill and Malamud (2014);

ii. information on relevant hazard interactions to populate the interaction framework (i.e. identifying how single hazards interact with each other), using the evidence in Sect. 2.2 to 2.6 and the matrix of globally possible interactions in Gill and Malamud (2014);

iii. an appropriate visualisation framework to represent hazard interactions; we adapt existing visualisation frameworks (Gill and Malamud, 2014, 2016, 2017) and ensure that these are appropriate to Guatemala.

We can then use this framework and evidence presented in Sect. 2 to identify potential networks of multi-hazard interactions and explore how anthropogenic processes can trigger natural hazards or catalyse hazard interactions (Gill and Malamud, 2017).

\section{Regional interaction frameworks (visualisations)}

We now proceed to develop our comprehensive, systematic, and evidenced regional interaction framework for Guatemala. In Sect. 3.1, we discuss the construction and population of regional interaction frameworks. In Sect. 3.2, we present a revised hazard classification scheme for Guatemala. In Sect. 3.3, we use this scheme and additional evidence to populate two regional interaction frameworks, a $21 \times 21$ hazard interaction matrix completed for a national spatial extent (Guatemala) and a $33 \times 33$ hazard interaction matrix completed for a sub-national spatial extent (southern Guatemalan Highlands). In Sect. 3.4, we use these frameworks and evidence from Sect. 2 to illustrate and discuss networks of multi-hazard interactions. In Sect. 3.5, we consider anthropogenic processes triggering hazards and catalysing interactions in Guatemala.

\subsection{Guiding the construction and population of regional interaction frameworks}

In Table 3, we explore, in the context of Guatemala, six themes laid out by Gill (2016) to guide the generation of regional interaction frameworks: spatial scale, temporal scale, likelihood-magnitude relationships, selection and classification of natural hazards, identifying relevant hazard interactions, and visualisation style and user communities. We integrate perspectives from hazard and civil-protection professionals in Guatemala (from semi-structured interviews and the workshop; see Sect. 2.5 and 2.6). Professional organisations have an understanding of local culture, language, and knowledge and have the mandate to adapt interaction frameworks into suitable forms for other stakeholders (e.g. policymakers and communities).

\subsection{Relevant natural hazards and hazard classification}

Gill and Malamud (2014) propose a broad classification of 21 natural hazards into six hazard groups (geophysical, hydrological, shallow Earth, atmospheric, biophysical, and space). This, or an alternative, comprehensive classification can be adapted to develop a regionally specific classification, using available evidence. We use this approach to propose a detailed, location-specific classification of natural-hazard types in Guatemala, building on evidence in Sect. 2. We begin by identifying which of the 21 natural hazards listed in Gill and Malamud (2014) are relevant in Guatemala and sub-divide selected hazards where evidence supports an expanded classification. We present our evidenced classification scheme in Table 4, including six natural-hazard groups, 19 hazard types, and 37 hazard sub-types. We also include an indication of the evidence types supporting this classification, using identifying letters A-E introduced in Sect. 2.1 and specific referenced publications and reports where appropriate. The 37 detailed natural-hazard sub-types in Table 4 help with improving the detail by which we can characterise interactions in regional interaction frameworks (e.g. see Sect. 3.3).

Our classification is one way of grouping relevant natural hazards, with alternative classifications possible. Other natural-hazard types may exist in Guatemala that have been missed from our classification, including those occurring less frequently or having a smaller impact than those we consider. We reduce the likelihood of missing key hazards by reviewing multiple evidence types to ensure a comprehensive and evidenced classification. We include 26 to 32 more hazard sub-types than existing regional interaction frameworks (e.g. Tarvainen et al., 2006; Kappes et al., 2010; Liu et al., 2016). In addition to the 37 natural-hazard sub-types in Table 4, we could also consider how a changing climate influences natural hazards (see McGuire and Maslin, 2012, for a full discussion) or include other hazard groups or processes, such as biological hazards (e.g. epidemics), technological hazards (e.g. structural collapse), or anthropogenic processes (e.g. vegetation removal). The latter are discussed in Sect. 3.5. 
Table 3. Consideration of six regional hazard interaction themes (identified in Gill, 2016) with respect to Guatemala. A description is given of how each theme is addressed in this regional interaction framework, using stakeholder comments discussed in Sect. 2.5 (interviews) and Sect. 2.6 (workshop results) to inform this process.

\begin{tabular}{|c|c|}
\hline Theme & Relevance in context of Guatemalan case study \\
\hline Spatial extent & $\begin{array}{l}\text { - Interview evidence suggested that national and sub-national spatial extents were suitable for } \\
\text { regional interaction frameworks. } \\
\text { - The southern Guatemalan Highlands, identified in Fig. 1, include large population centres and } \\
\text { critical infrastructure. We therefore produce regional interaction frameworks for Guatemala } \\
\text { (using political boundaries) and the southern Guatemalan Highlands (using non-political } \\
\text { boundaries). } \\
\text { - For both national and sub-national scales, we consider hazards and interactions that cut } \\
\text { across the determined boundaries. }\end{array}$ \\
\hline Temporal extent & $\begin{array}{l}\text { - Interview evidence suggested that regional interaction frameworks be developed for both } \\
\text { preparation (before a primary event) and response (immediate aftermath of a primary event). } \\
\text { - Not all of the natural hazards and interactions will be relevant at any given time. } \\
\text { - The temporal relevance of interactions may change given a changing set of anthropogenic } \\
\text { processes relevant to this region. } \\
\text { - The temporal relevance of interactions may also change in response to natural and human-driven } \\
\text { climate change. } \\
\text { - The regional interaction frameworks should be viewed as being dynamic and regularly } \\
\text { reviewed and updated to remain relevant. }\end{array}$ \\
\hline $\begin{array}{l}\text { Likelihood-magnitude } \\
\text { relationships }\end{array}$ & $\begin{array}{l}\text { - Interview evidence suggested a desire for additional information on likelihood-magnitude } \\
\text { relationships of interactions. This could be done through an expert elicitation method once a } \\
\text { completed interaction framework is prepared. } \\
\text { - Interaction matrices published in this paper can be taken and additional layers of complexity } \\
\text { added, according to user requirements. This could include information on likelihood-magnitude } \\
\text { relationships or other parameters of interest (e.g. mitigation approaches). }\end{array}$ \\
\hline $\begin{array}{l}\text { Selection and classification } \\
\text { of hazards }\end{array}$ & $\begin{array}{l}\text { - Interview evidence suggested that an expanded natural-hazard classification would improve } \\
\text { understanding and communication of potential hazard interactions. We therefore develop an } \\
\text { expanded classification of natural hazards in Sect. } 3.2 \text {. } \\
\text { - The review of a broad range of evidence types allows the identification of multiple relevant } \\
\text { hazards, seeking to be as comprehensive as possible rather than focusing on specific natural } \\
\text { hazard groups. } \\
\text { - } 17 \text { of } 21 \text { interview participants (Sect. } 2.5 \text { ) noted anthropogenic processes to be important for } \\
\text { consideration, and we discuss these in Sect. } 3.5 \text {. }\end{array}$ \\
\hline $\begin{array}{l}\text { Identifying relevant hazard } \\
\text { interactions }\end{array}$ & $\begin{array}{l}\text { - Workshop evidence indicated different stakeholder opinions on the relevance of specific hazard } \\
\text { interactions in Guatemala. The use of multiple evidence types can help with populating regional } \\
\text { interaction frameworks in a systematic manner. }\end{array}$ \\
\hline $\begin{array}{l}\text { Visualisation style and user } \\
\text { communities }\end{array}$ & $\begin{array}{l}\text { - Interview evidence suggested that a matrix visualisation format would be suitable for hazard and } \\
\text { civil-protection professionals, our intended user group. } \\
\text { - We prepared frameworks in English, but these can subsequently be translated into Spanish. } \\
\text { Explanations of vocabulary can accompany interaction visualisations. }\end{array}$ \\
\hline
\end{tabular}

\subsection{Guatemala interaction frameworks}

Building upon the reflections in Sect. 3.1, and using the hazard classification in Sect. 3.2 and evidence in Sect. 2, we now construct and populate interaction frameworks for two different spatial extents in Guatemala:

1. National spatial extent (Sect. 3.3.1). We produce a $21 \times$ 21 interaction framework (matrix form), with 16 relevant primary hazards and 15 relevant secondary haz- ards. We initially constrain interactions for a national spatial extent using the Gill and Malamud (2014) hazard classification (21 hazard types).

2. Sub-national (southern Guatemalan Highlands) spatial extent (Sect. 3.3.2). We produce an interaction framework (matrix form) using our classification of 37 hazard sub-types, giving a maximum of 37 primary and 37 secondary hazards. We use information from Sect. 2 to (i) explain and justify the selection of the south- 


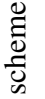

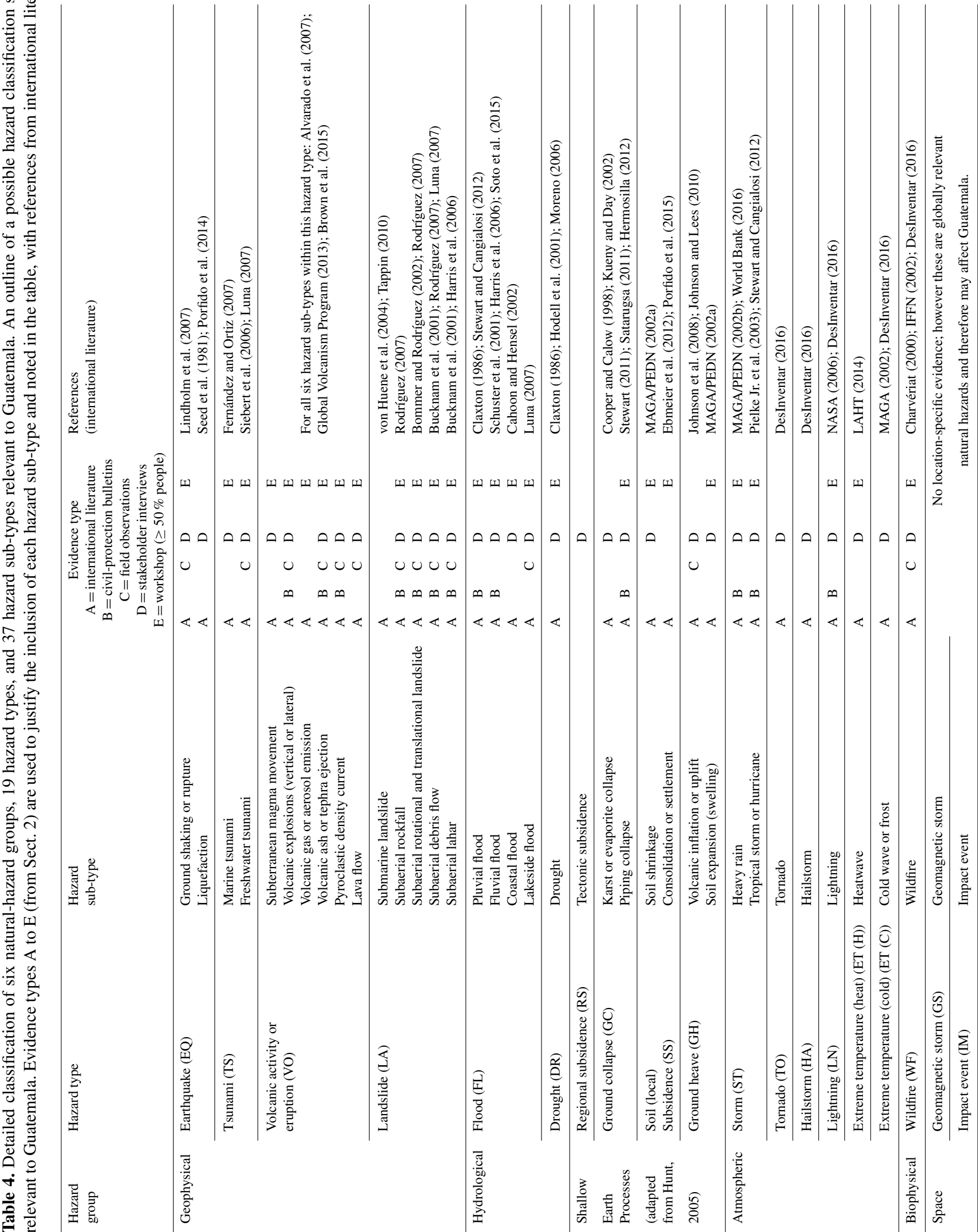


ern Guatemalan Highlands, (ii) determine which of the 37 hazard sub-types are relevant in this spatial extent, and (iii) adapt the $21 \times 21$ interaction framework to incorporate these hazard sub-types and populate this framework with relevant hazard interactions.

Both interaction frameworks use a matrix visualisation approach.

\subsubsection{Guatemala national $21 \times 21$ interaction framework (matrix form)}

To develop an interaction framework for the national spatial extent of Guatemala, we start with an existing $21 \times 21$ hazard interaction matrix (Gill and Malamud, 2014). From Table 4 we identify that 19 of the 21 natural hazards in this matrix are relevant to Guatemala. Using the evidence in Sect. 2, we systematically examine each matrix cell to consider whether an interaction is possible in Guatemala. We present our completed national-scale, regional interaction framework in Fig. 3, with 21 primary natural hazards on the vertical axis (of which 16 are relevant) and the same 21 secondary (of which 15 are relevant) natural hazards on the horizontal axis; 50 (11\%) of 441 cells are shaded, indicating 50 possible interactions. These include the following:

i. Triggering only. This represents $15(30 \%)$ of the 50 interactions.

ii. Increased probability only. This represents $5(10 \%)$ of the 50 interactions.

iii. Triggering and increased probability. This represents $30(60 \%)$ of the 50 interactions.

The evidence types (A-E) given in Sect. 2 supporting these 50 hazard interactions are outlined in Table S5. We believe that this to be the first national-scale assessment of possible hazard interactions in the peer-reviewed literature, with our approach being generalisable for other national contexts. We use Table S5 to inform the development of an additional national-scale $21 \times 21$ matrix to communicate uncertainty regarding each interaction, which is also presented in Fig. S5. This additional matrix demonstrates the importance of a multi-method approach, integrating diverse evidence types to explain relevant hazard interactions. Analysing any one evidence type (A-E) would only identify a sample of relevant interactions. Table S5 shows that 13 (26\%) of 50 relevant interactions were identified in the workshop of civilprotection professionals, $9(18 \%)$ using civil-protection bulletins, $28(56 \%)$ using interviews with hazard professionals, and $32(64 \%)$ using international literature. Developing comprehensive regional interaction frameworks requires multiple, diverse evidence types.

\subsubsection{Southern Guatemalan Highlands $33 \times 33$ interaction framework (matrix form)}

We now proceed to develop a regional interaction framework for a sub-national spatial extent. Using physiography, we divide Guatemala into four spatial regions as indicated in Fig. 1: (1) low-relief northern plateau, (2) central Guatemalan Highlands, with deep valleys, (3) southern Guatemalan Highlands, and the (4) Pacific Coastal Plain. In Table 5, we show the 37 hazard sub-types described in Sect. 3.2 and use the evidence types (A-E) given in Sect. 2 to characterise their spatial relevance to these four regions. More hazards are spatially relevant to the southern Guatemalan Highlands than other regions in Guatemala; $33(89 \%)$ of 37 possible hazard sub-types are possible in the southern Guatemalan Highlands, compared with $26(70 \%)$ to $27(73 \%)$ of 37 hazard sub-types relevant in the other regions. The southern Guatemalan Highlands are a region of variable topography between the Pacific Coast and the Polochic-Motagua-Chamalecón fault system. It incorporates the volcanic arc, with at least three active volcanic systems (Pacaya, Fuego, and Santiaguito).

The 33 hazard sub-types relevant in the southern Guatemalan Highlands are used as primary and secondary hazards in our regional interaction framework. This results in $1089(33 \times 33)$ possible interactions between these hazard sub-types. Using existing global interaction frameworks (i.e. Gill and Malamud, 2014) and evidence in Sect. 2, we systematically examine each cell to determine if an interaction could or could not occur. In Fig. 4 we present this $33 \times 33$ sub-national interaction framework for the southern Guatemalan Highlands. Figure 4 includes 114 (10\%) of 1089 cells shaded, indicating 114 possible interactions. These include the following:

i. Triggering only. This represents 26 (23\%) of 114 interactions.

ii. Increased probability only. This represents 15 (13\%) of 114 interactions.

iii. Triggering and increased probability. This represents $73(64 \%)$ of 114 interactions.

The 114 interactions in Fig. 4 include interactions that occur over large and small spatial areas, with both high and low frequencies and both high- and low-magnitude events. The temporal relevance of interactions in Fig. 4 may change, for example due to evolving anthropogenic activity (see Sect. 3.5) or environmental change. Interactions include some originating outside of the spatial region of interest and others that may propagate outside. For example, (i) an earthquake north of the southern Guatemalan Highlands may result in ground shaking, liquefaction, landslides, and other secondary hazards inside the southern Guatemalan Highlands; (ii) lahars triggered in the southern Guatemalan Highlands may trigger 


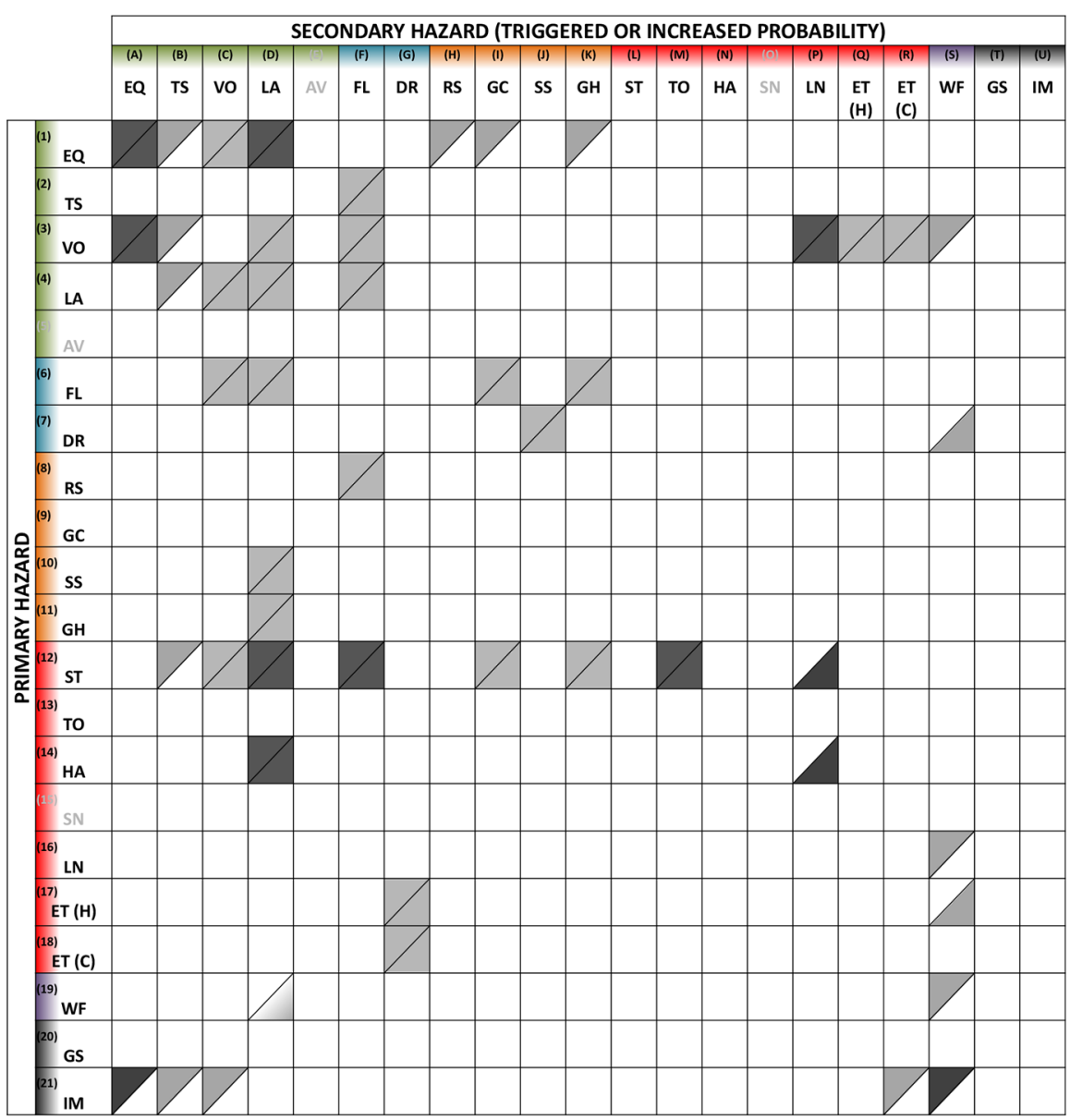

Footnotes

[1B, 4B] Earthquakes and landslides may trigger marine and/or freshwater (lake) tsunamis.

[1C,H; 12M] There was uncertainty about the nature of these relationships.

$[\mathbf{1 I}, \mathbf{K}]$ Earthquakes may trigger collapse or heave primarily through liquefaction.

[3B] Volcanic explosions may trigger freshwater tsunamis in the lakes of Guatemala.

[3Q/R] Volcanic eruptions can trigger temperature changes if they are of sufficient magnitude.

$[6,12 \mathrm{C}]$ Water input triggers or increases the probability of a phreatic or phreatomagmatic eruption.

[8F] Although regional subsidence triggering flooding was not noted in any evidence source consulted, this is an inevitable consequence of the lowering of the ground surface.

[12B] Pressure changes associated with storms may trigger meteotsunamis in marine environments.

[21A-C,R,S] Identified as being generally possible, supported by globally relevant literature rather than location-specific evidence.

Figure 3. National interaction framework for Guatemala. A $21 \times 21$ matrix with 21 primary natural hazards on the vertical axis and the same 21 natural hazards presented as secondary hazards on the horizontal axis. Hazard type abbreviations (e.g. SN) shaded grey are determined as not being relevant in Guatemala. Interactions (shaded triangles in cells) include primary hazards triggering a secondary hazard (upper left triangle shaded in cell) and primary hazards increasing the probability of a secondary hazard occurring (lower right triangle shaded in cell). This matrix is populated using different evidence types, as outlined in Sect. 2. Visualisation structure based on Gill and Malamud (2014). See also an additional matrix in Fig. S5, showing the number of evidence types used for each hazard interaction pairing when populating Fig. 3.

flooding outside of the southern Guatemalan Highlands, in the Pacific Coastal Plain; and (iii) large volcanic eruptions in the southern Guatemalan Highlands can eject ash and tephra far beyond this extent. Characteristics of interactions (e.g. likelihood) are not included in Fig. 4 but could be added as additional information layers if further research results were available.

\subsection{Networks of multi-hazard interactions (cascades)}

In addition to one hazard triggering or increasing the probability of another hazard, longer linear or non-linear networks of multi-hazard interactions (or cascades) can also occur (Han et al., 2007; Choine et al., 2015; Gill and Malamud, 2016; Pescaroli and Alexander, 2018). These network events have both spatial and temporal dimensions, include both 


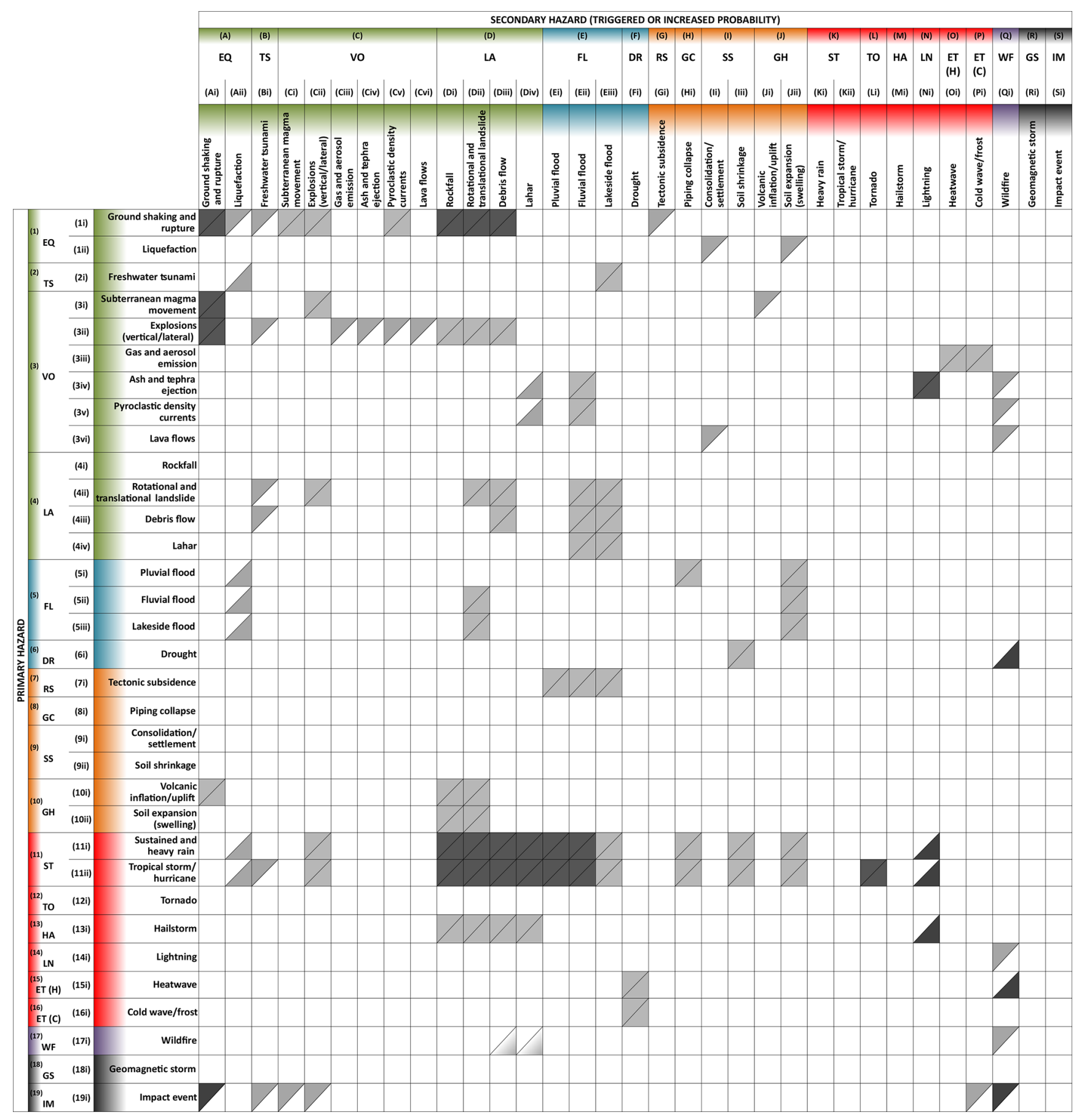

Figure 4. Southern Guatemalan Highlands (sub-national) interaction framework, Guatemala. A $33 \times 33$ matrix with 33 primary natural-hazard sub-types on the vertical axis, and the same 33 natural-hazard sub-types presented as secondary hazards on the horizontal axis. Interactions (shaded triangles in cells) include primary hazards triggering a secondary hazard (upper left triangle shaded in cell) and primary hazards increasing the probability of a secondary hazard occurring (lower right triangle shaded in cell). This matrix is populated using different evidence types, as outlined through Sect. 2. See Fig. 3 legend for symbols and coding. 
Table 5. Spatial distribution of 37 natural-hazard sub-types in Guatemala. A synthesis table to characterise which regions in Guatemala are susceptible to each of the 37 natural-hazard sub-types. Selected regions (see Fig. 1) are (1) low-relief northern plateaus, (2) central Guatemalan Highlands, with deep valleys, (3) southern Guatemalan Highlands, and (4) Pacific Coastal Plain.

\begin{tabular}{|c|c|c|c|c|c|c|c|c|}
\hline \multirow[t]{3}{*}{$\begin{array}{l}\text { Hazard } \\
\text { group } \\
\\
\text { Geophysical }\end{array}$} & \multirow[t]{3}{*}{$\begin{array}{l}\text { Hazard type } \\
\text { Earthquake (EQ) }\end{array}$} & \multirow{3}{*}{$\begin{array}{l}\text { Hazard sub-type } \\
\\
\text { Ground shaking or rupture } \\
\text { Liquefaction }\end{array}$} & \multirow{3}{*}{$\begin{array}{l}\text { Spatial } \\
\text { regions } \\
(1,2,3,4) \\
\\
1,2,3,4 \\
1,2,3,4\end{array}$} & \multicolumn{5}{|c|}{$\begin{array}{c}\text { Evidence type } \\
\mathrm{A}=\text { international literature } \\
\mathrm{B}=\text { civil-protection bulletins } \\
\mathrm{C}=\text { field observations } \\
\mathrm{D}=\text { stakeholder interviews } \\
\mathrm{E}=\text { workshop }(\geq 50 \% \text { people })\end{array}$} \\
\hline & & & & A & & $\mathrm{C}$ & $\mathrm{D}$ & $\mathrm{E}$ \\
\hline & & & & A & & & $\mathrm{D}$ & \\
\hline & \multirow[t]{2}{*}{ Tsunami (TS) } & Marine tsunami & 2,4 & A & & & $\mathrm{D}$ & $\mathrm{E}$ \\
\hline & & Freshwater tsunami & $1,2,3$ & A & & $\mathrm{C}$ & $\mathrm{D}$ & $\mathrm{E}$ \\
\hline & \multirow{6}{*}{$\begin{array}{l}\text { Volcanic activity or eruption } \\
\text { (VO) }\end{array}$} & Subterranean magma movement & 3 & A & & & $\mathrm{D}$ & $\mathrm{E}$ \\
\hline & & Volcanic explosions (vertical or lateral) & 3 & A & $\mathrm{B}$ & $\mathrm{C}$ & $\mathrm{D}$ & $\mathrm{E}$ \\
\hline & & Volcanic gas or aerosol emission & 3 & A & & & & $\mathrm{E}$ \\
\hline & & Volcanic ash or tephra ejection & $1,2,3,4$ & A & $\mathrm{B}$ & $\mathrm{C}$ & $\mathrm{D}$ & $\mathrm{E}$ \\
\hline & & Pyroclastic density current & 3 & A & $\mathrm{B}$ & $\mathrm{C}$ & $\mathrm{D}$ & $\mathrm{E}$ \\
\hline & & Lava flow & 3 & A & & $\mathrm{C}$ & $\mathrm{D}$ & $\mathrm{E}$ \\
\hline & \multirow[t]{5}{*}{ Landslide (LA) } & Submarine landslide & 2,4 & A & & & & \\
\hline & & Subaerial rockfall & $1,2,3,4$ & A & $\mathrm{B}$ & $\mathrm{C}$ & $\mathrm{D}$ & $\mathrm{E}$ \\
\hline & & Subaerial rotational and translational landslide & $1,2,3,4$ & A & B & $\mathrm{C}$ & $\mathrm{D}$ & $\mathrm{E}$ \\
\hline & & Subaerial debris flow & $1,2,3,4$ & A & $\mathrm{B}$ & $\mathrm{C}$ & $\mathrm{D}$ & $\mathrm{E}$ \\
\hline & & Subaerial lahar & 3 & A & $\mathrm{B}$ & $\mathrm{C}$ & $\mathrm{D}$ & $\mathrm{E}$ \\
\hline \multirow[t]{5}{*}{ Hydrological } & \multirow[t]{4}{*}{ Flood (FL) } & Pluvial flood & $1,2,3,4$ & A & $\mathrm{B}$ & & $\mathrm{D}$ & $\mathrm{E}$ \\
\hline & & Fluvial flood & $1,2,3,4$ & A & $\mathrm{B}$ & $\mathrm{C}$ & $\mathrm{D}$ & $\mathrm{E}$ \\
\hline & & Coastal flood & 2,4 & A & & & $\mathrm{D}$ & $\mathrm{E}$ \\
\hline & & Lakeside flood & $1,2,3$ & A & & $\mathrm{C}$ & $\mathrm{D}$ & $\mathrm{E}$ \\
\hline & Drought (DR) & Drought & $1,2,3,4$ & A & & & $\mathrm{D}$ & $\mathrm{E}$ \\
\hline \multirow{3}{*}{$\begin{array}{l}\text { Shallow Earth } \\
\text { Processes } \\
\text { (adapted from }\end{array}$} & Regional subsidence (RS) & Tectonic subsidence & $1,2,3,4$ & & & & $\mathrm{D}$ & \\
\hline & \multirow[t]{2}{*}{ Ground collapse (GC) } & Karst or evaporite collapse & 1 & A & & & $\mathrm{D}$ & \\
\hline & & Piping collapse & 3 & A & $\mathrm{B}$ & & $\mathrm{D}$ & $\mathrm{E}$ \\
\hline \multirow[t]{4}{*}{ Hunt, 2005) } & \multirow[t]{2}{*}{ Soil (local) subsidence (SS) } & Soil shrinkage & 1,4 & A & & & $\mathrm{D}$ & $\mathrm{E}$ \\
\hline & & Consolidation or settlement & $1,2,3,4$ & A & & & & $\mathrm{E}$ \\
\hline & \multirow[t]{2}{*}{ Ground heave $(\mathrm{GH})$} & Volcanic inflation or uplift & 3 & A & & $\mathrm{C}$ & $\mathrm{D}$ & \\
\hline & & Soil expansion (swelling) & $1,2,3,4$ & A & & & $\mathrm{D}$ & $\mathrm{E}$ \\
\hline \multirow[t]{7}{*}{ Atmospheric } & \multirow[t]{2}{*}{ Storm (ST) } & Heavy rain & $1,2,3,4$ & A & & $\mathrm{B}$ & $\mathrm{D}$ & $\mathrm{E}$ \\
\hline & & Tropical storm or hurricane & $1,2,3,4$ & A & $\mathrm{B}$ & & $\mathrm{D}$ & $\mathrm{E}$ \\
\hline & Tornado (TO) & Tornado & $1,2,3,4$ & A & & & $\mathrm{D}$ & \\
\hline & Hailstorm (HA) & Hailstorm & $1,2,3,4$ & A & & & $\mathrm{D}$ & \\
\hline & Lightning (LN) & Lightning & $1,2,3,4$ & A & $\mathrm{B}$ & & $\mathrm{D}$ & $\mathrm{E}$ \\
\hline & Extreme temperature (heat; ET $(\mathrm{H}))$ & Heatwave & $1,2,3,4$ & A & & & $\mathrm{D}$ & $\mathrm{E}$ \\
\hline & Extreme temperature (cold; ET (C)) & Cold wave or frost & $1,2,3,4$ & A & & & $\mathrm{D}$ & \\
\hline Biophysical & Wildfire (WF) & Wildfire & $1,2,3,4$ & A & & $\mathrm{C}$ & $\mathrm{D}$ & $\mathrm{E}$ \\
\hline \multirow[t]{2}{*}{ Space } & Geomagnetic storm (GS) & Geomagnetic storm & $1,2,3,4$ & & & & & \\
\hline & Impact event (IM) & Impact event & $1,2,3,4$ & & & & & \\
\hline
\end{tabular}

high- and low-likelihood events, and have diverse impacts. Ciurean et al. (2018) outline a range of methods for qualitatively and quantitatively characterising such multi-hazard interaction network events. For example, event scenario trees can be used to assess the probabilities of specific hazard cascades (Neri et al., 2008, 2013).
The evidence we present in Sect. 2 includes many examples of multi-hazard interaction network events. For example, the internationally published literature characterising the $1976 M_{\mathrm{W}}=7.5$ Guatemala earthquake clearly articulates a set of triggered hazards. After the earthquake, there were multiple aftershocks and movement on other faults close to 
Guatemala City as well as rapid subsidence or ground collapse (Espinosa, 1976; Plafker et al., 1976). The earthquake triggered more than 10000 landslides, rockfalls, and debris flows, blocking vital transport routes (Plafker et al., 1976; Harp et al., 1981) and blocking rivers to trigger upstream flooding (Plafker et al., 1976; Harp et al., 1981). Breaches of these landslide dams also resulted in further flooding (Harp et al., 1981).

The civil-protection bulletins characterised in Sect. 2.3 also include several examples of events consisting of multihazard interactions in Guatemala. These include events with primary, secondary, and tertiary hazards as well as events reporting primary hazards changing the likelihood of future hazards. Table 6 gives three diverse examples of network events derived from Table S2, demonstrating the complexity of hazard interaction networks in Guatemala. Table 6 also includes a simple visualisation of each example, showing the range of hazards and interaction relationships:

i. linear events where one primary hazard triggers one secondary hazard which triggers one tertiary hazard (Example 1),

ii. multi-branch events where a primary hazard may trigger multiple secondary hazards, each triggering one or more tertiary hazards (Example 2),

iii. a primary hazard triggering and increasing the likelihood of multiple secondary hazards during a highmagnitude, complex event, replicated in multiple areas of Central America (Example 3).

Further examples of hazard interaction network events emerged from stakeholder interviews, including volcanic eruptions and heavy rain triggering lahars, which subsequently trigger floods. These networks can be visualised using interaction frameworks, as illustrated in Figs. 5 and 6:

i. Case Study 1 (Fig. 5). This example is from Santiaguito and was identified in multiple stakeholder interviews (supported by other evidence). On an annual basis, during the rainy season, while Santiaguito is active and generates large volumes of tephra, lahars can (and have been) triggered on the flanks of Santiaguito, which results in severe erosion and triggers flooding. This example features in evidence in Sect. 2.2, 2.4, and 2.5.

ii. Case Study 2 (Fig. 6). Hurricane Stan (2005) triggered a debris flow in the mountains adjacent to Lake Atitlán, with this debris flow triggering a tsunami, which caused a small lakeside flood. This example featured in evidence in Sect. 2.2, 2.4, and 2.5. This description is based on a specific event in 2005, Hurricane Stan (Luna, 2007).

The regional interaction frameworks we present in this paper can help with visualising case studies of cascades identified through various evidence types and identify potential scenarios where networks of multi-hazard interactions might occur, given a primary hazard. For example, given a large earthquake, the possible scenarios that may arise could be visualised using Figs. 3 and 4 and evaluated by hazard professionals. Gill and Malamud (2016) outlined three reasons why the assessment and visualisation of possible multi-hazard interaction network scenarios are of importance to both the theoretical and practical understanding of hazards and disaster risk reduction. These three reasons are as follows:

i. Assessing, managing, and reducing disaster risk require better modelling of the natural environment by moving from understanding discrete, independent events to matching the observed reality by including interaction networks.

ii. Identifying possible multi-hazard interaction network scenarios may allow improvements to disaster preparedness by better assessing how vulnerability will change during successive hazard events. Aspects of social and/or physical vulnerability may change following the occurrence of a specific natural hazard (e.g. volcanic eruption), before the triggered hazard (e.g. raintriggered lahars) occurs.

iii. Understanding how multi-hazard interaction network events are initiated and propagated may help determine how to invest resources to minimise disruption should a specific network of interacting hazards occur.

\subsection{Anthropogenic processes}

In Sect. 3.2 to 3.4 , we primarily consider interactions between natural hazards; however, anthropogenic processes can also trigger natural hazards and influence natural-hazard interactions (Glade, 2003; Knapen et al., 2006; Owen et al., 2008; Gill and Malamud, 2017). Information on relevant anthropogenic processes can support hazard and civilprotection professionals in evaluating how anthropogenic activity may trigger hazards and influence hazard interactions.

Using a classification of 18 anthropogenic processes (Gill and Malamud, 2017), and evidence from Sect. 2, we identify 17 relevant anthropogenic processes in Guatemala, listed in Table S6. Some of these processes are only relevant for small spatial extents (e.g. individual towns), with others being more widespread (e.g. in many populated regions). Table S6 includes the evidence types (A-E) from Sect. 2 used to justify their relevance to Guatemala. Some anthropogenic processes feature multiple times within one evidence type. For example, four interviewees noted road construction (infrastructure construction: unloading) and four noted deforestation (vegetation removal) in the context of triggering landslides. In contrast, only one interview participant mentioned groundwater abstraction as a potential trigger of subsidence. 


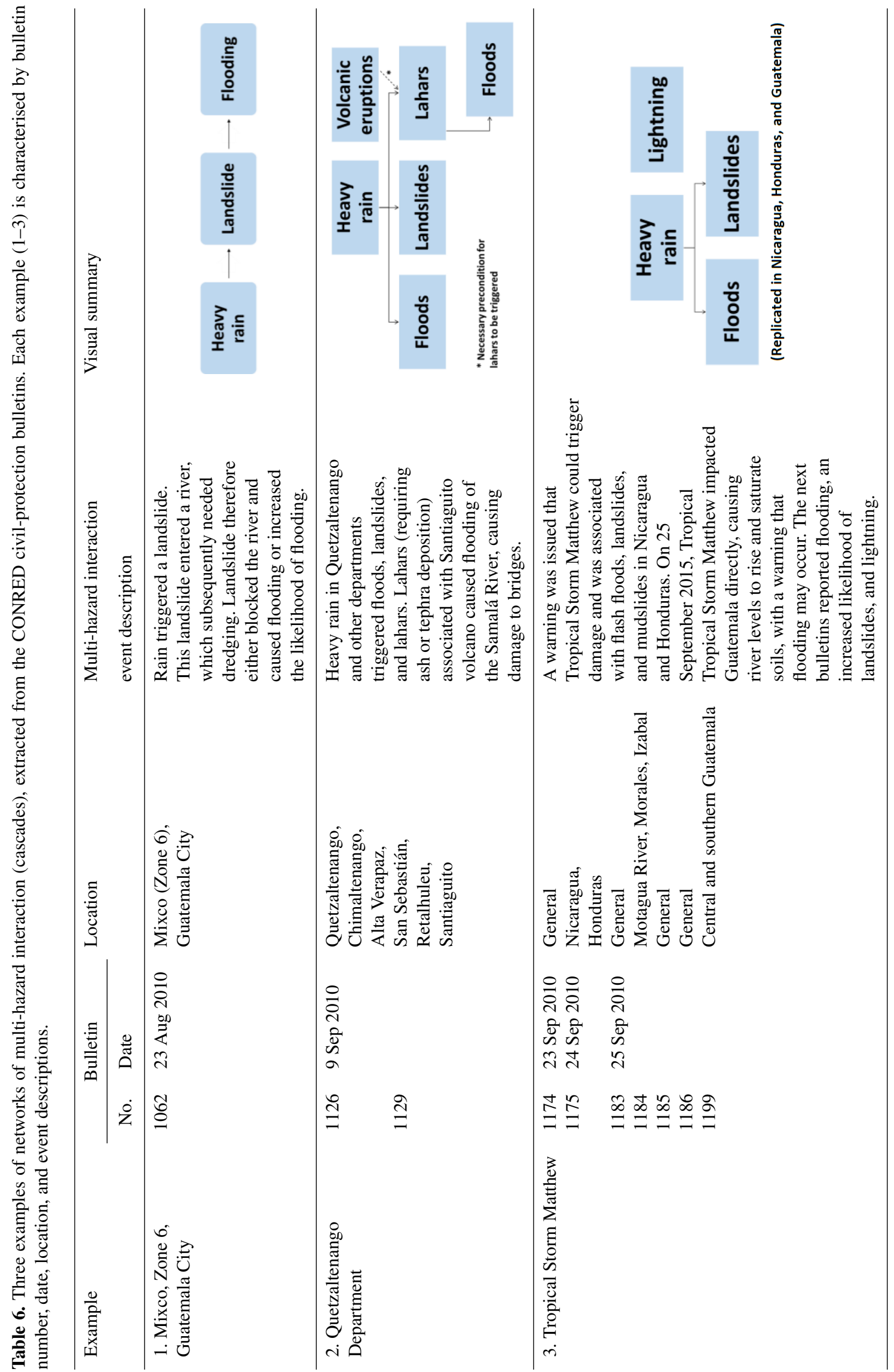




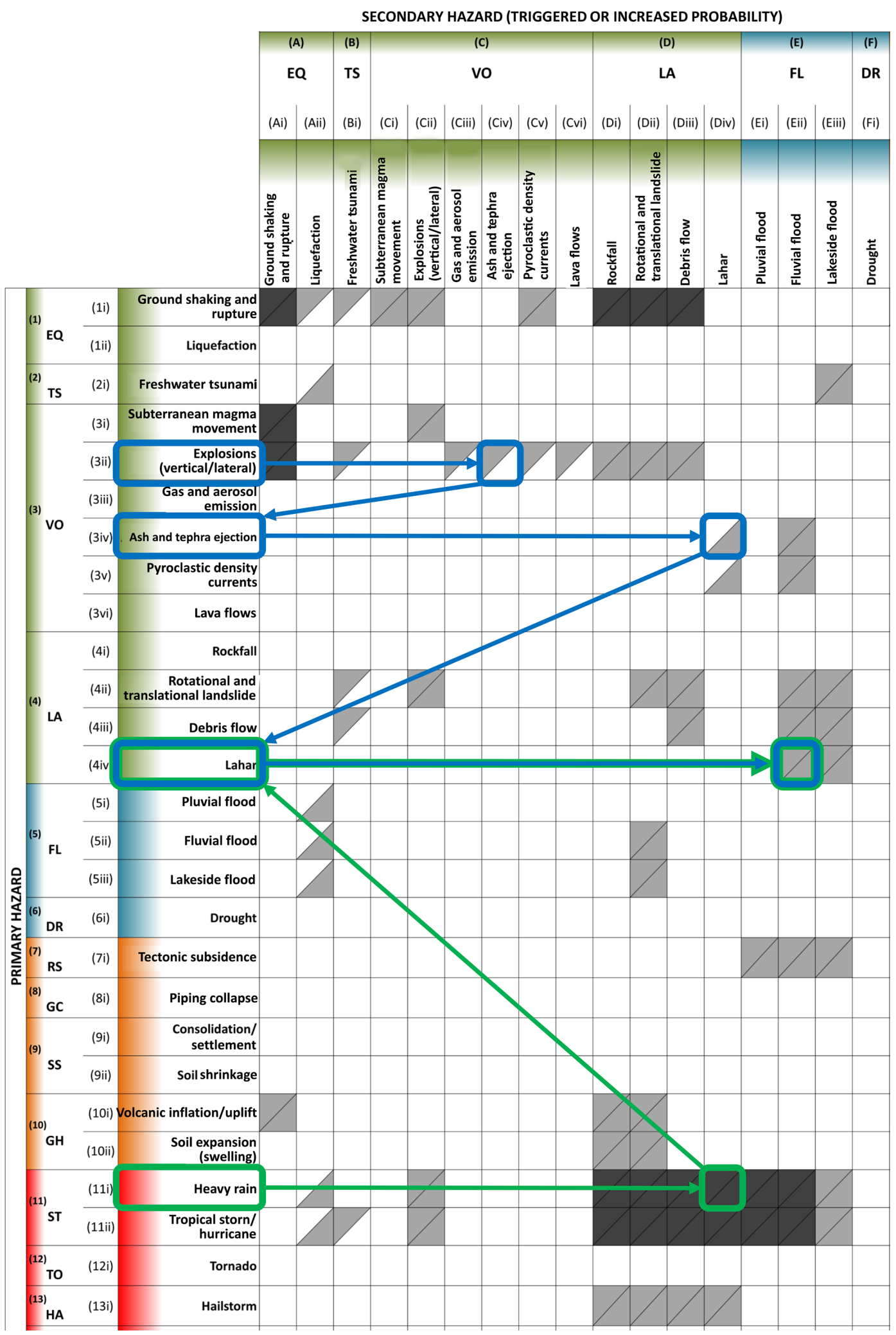

Figure 5. Network of hazard interactions (Example 1), southern Guatemalan Highlands, Guatemala. A $26 \times 17$ extract of the $33 \times 33$ subnational interaction framework presented in Fig. 4, with a case-study example of a network of hazard interactions (cascade). This case study shows (i) volcanic explosions triggering the ejection of ash and tephra, (ii) ash and tephra increasing the likelihood of lahars, (iii) heavy rain (together with the existing tephra and ash) combining to trigger a lahar, and (iv) lahars triggering flooding. Evidence for this network is stated in the text. See Fig. 3 legend for symbols and coding. 


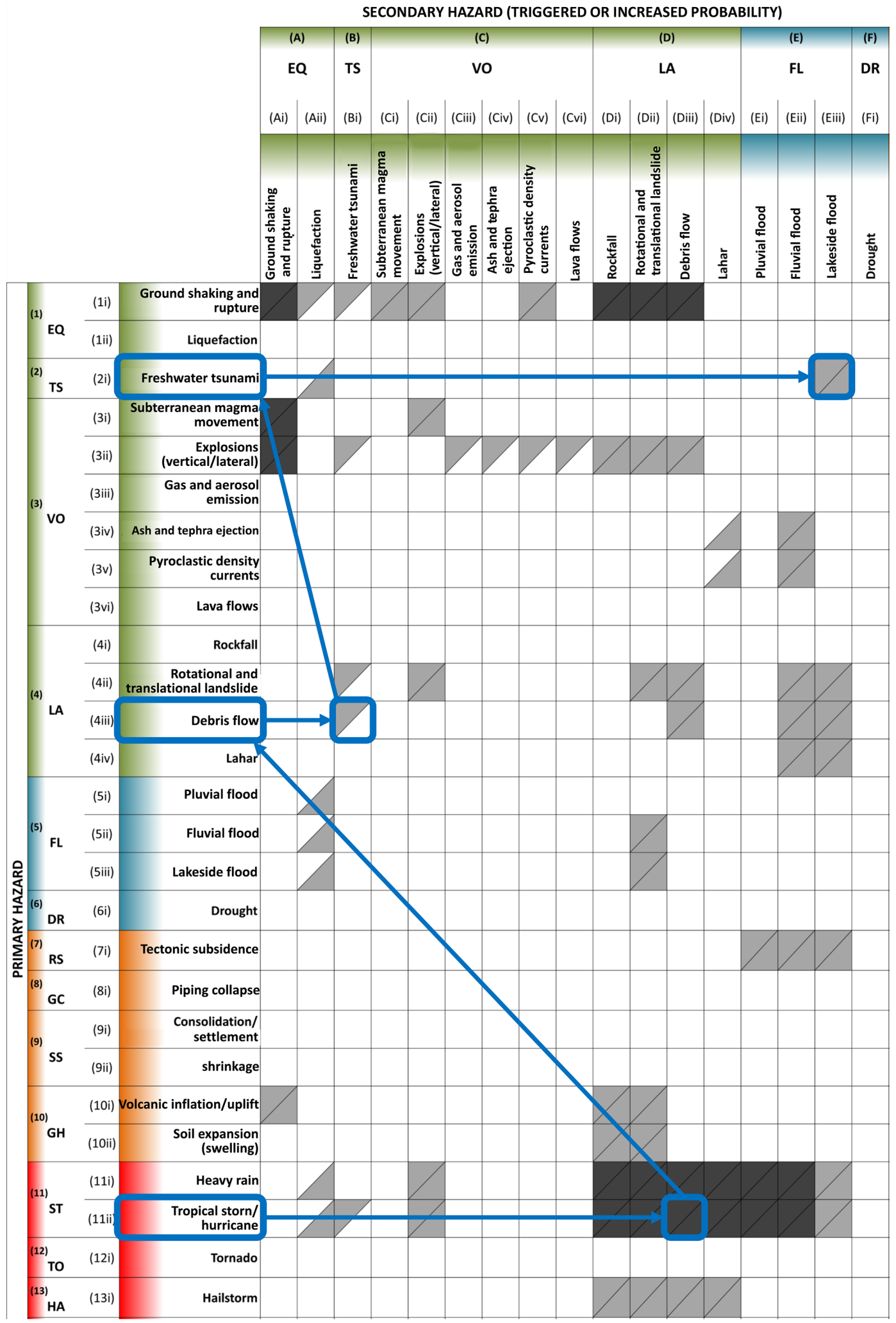

Figure 6. Network of hazard interactions (Example 2), southern Guatemalan Highlands, Guatemala. A $26 \times 17$ extract of the $33 \times 33$ subnational interaction framework presented in Fig. 4, with a case-study example of a network of hazard interactions (cascade). This case-study example shows (i) Hurricane Stan (October 2005) triggering a debris flow, (ii) debris flows triggering a freshwater tsunami in Lake Atitlán, and (iii) freshwater tsunami triggering a lakeside flood. Evidence for this network is stated in the text. See Fig. 3 legend for symbols and coding. 
The spatial and temporal relevance of these 17 anthropogenic processes will vary and could change over time. Anthropogenic processes can start and stop and both grow and shrink in their spatial extent. The anthropogenic processes in Table S6 should be regularly reviewed to assess their relevance, if other processes have started, and if there are any consequences of this variation on natural hazards and hazard interactions. For example, increased road construction may change the likelihood of landslides during heavy rain.

\subsection{Regional interaction framework summary}

We have integrated diverse evidence types regarding hazards and hazard interactions in Guatemala and unified them in a formal structure, supported by expert knowledge. We have collated information on relevant single hazards and appropriate ways to classify these in Guatemala and information on relevant hazard interactions. Using a comprehensive and systematic approach, we have constructed evidenced national and sub-national interaction frameworks in matrix form, considering hazard interaction networks and relevant anthropogenic processes. We have demonstrated that our approach is scalable (with national and sub-national applications described) and therefore suggest that it is reproducible in diverse geographical contexts and at multi-national to local scales. Regional interaction frameworks provide a comprehensive overview of potential hazard interactions that allow agencies responsible for hazard monitoring and response to assess if current disaster risk reduction and response strategies, and communication and collaboration mechanisms, can be enhanced to recognise the complexity represented.

\section{Discussion}

In this discussion section, we first explain how the approach to constructing regional interaction frameworks we have developed in this paper can be replicated and scaled in diverse settings (Sect. 4.1). We proceed to explore how regional interaction frameworks can be used to enhance understanding of multi-hazard interactions (Sect. 4.2) and opportunities to enhance regional interaction frameworks through new research and practice (Sect. 4.3).

\subsection{Scalability and relevance of regional interaction frameworks for disaster risk reduction}

The interdisciplinary, multi-method approach we have laid out in Sects. 1 to 3 is scalable and can be applied in diverse geographical settings to generate a comprehensive, systematic, evidenced review of potential hazard interactions. A synthesis of available evidence in any given context (e.g. multi-national, national, and sub-national) is necessary for underpinning the construction of regional interaction frameworks. Our approach first develops an extensive location-specific hazard classification and then populates a customised matrix with information about relevant hazard interactions. This contrasts with many existing studies of multihazards which are often focused on the layering of single hazards but not looking at the potential interactions. When potential hazard interactions are considered, most studies are not systematic and are selective about which hazards they include. The studies often do not describe the evidence for including or excluding certain hazards or interactions between hazards. The regional interaction frameworks we present in Sect. 3 include 21 to 33 natural hazards, compared to 6 to 11 natural hazards in the examples summarised in Table 1.

Other countries in Central America (e.g. Nicaragua, El Salvador, and Costa Rica) have similarities to Guatemala in their multi-hazard landscape. Their national interaction frameworks would likely be similar, although not identical, to Guatemala. Interaction frameworks for other countries may look very different, shaped by the tectonic and meteorological setting. Regional interaction frameworks can also be developed for sub-national scales, including large geographical domains, municipalities, or localised sites important to the development of critical infrastructure.

We propose that comprehensive, systematic, and evidenced regional interaction frameworks can improve awareness of complex multi-hazard landscapes and assessment of potential networks of hazard interactions, thus informing disaster risk reduction and response strategies. Detailed and evidenced reviews of multi-hazard interactions are a fundamental first step in understanding the complexity of the multihazard landscape and therefore understanding risk (Sendai Framework, Priority for Action 1). In particular, regional interaction frameworks can be a powerful tool for scenario discussions between hazard managers and those responsible for single hazard preparedness and response. Through sitting down and discussing together the potential multi-hazard scenarios that may occur, decisions can be made about the preparedness steps required and how different actors would work together to respond. It may be possible to indicate which scenarios have a high likelihood vs. a low likelihood and which could have a large impact vs. a small impact. When the regional interaction frameworks were used by us in this way in Guatemala during a visit of the first author in 2018, some participants questioned the inclusion of particular hazards and/or hazard interactions in the interaction frameworks (e.g. landslides triggering tsunamis). Following discussion of the evidence used to populate the matrix for this scenario, participants reported changes in opinion about the relevance of these interactions and their need for inclusion within planning.

Further examples of how the information within regional interaction frameworks, and generated scenarios, can be used by agencies responsible for hazard monitoring, DRR, and disaster response are as follows.

- Scenarios to ensure hazard preparedness and disaster response systems are effective. The occurrence of 
one hazard (e.g. a volcanic eruption) may result in the movement of people or assets to another region. Ensuring comprehensive awareness within decision-making agencies of how this hazard has changed the likelihood of other hazards (e.g. lahars and landslides) is necessary for ensuring that exposure and vulnerability of displaced people are not increased. Developing and discussing scenarios of triggered hazard scenarios, particularly with diverse single-hazard actors all taking part in the discussion, can help explore dynamic vulnerability between successive hazard events and the steps needed to prevent compounding impacts.

- Scenarios as an aid for land-use planning. Urban development is growing in many parts of the world, with cities expanding rapidly. We believe that these regional interaction frameworks can be used as scenarios by land-use planners to be much more aware of the multihazard landscape and potential multi-hazard interactions and bring this into their planning. These frameworks can help inform urban planning by creating scenarios where there is the potential for interactions between spatially overlapping or contiguous hazards. This can then help in ensuring that risk is not underestimated and building effective hazard management plans that consider potential cascades of hazards. For example, an underground transport system may need to consider how an earthquake triggering subsidence would affect its susceptibility to groundwater flooding.

- Educational and preparedness messages delivered to communities. Many communities are exposed to multiple hazards. Understanding the physical processes that underpin these hazards and the steps they can take to reduce their risk is acknowledged as important within the Sendai Framework guiding principles (UNDRR, 2015). Building awareness through multiple separate communications, for individual hazards, may result in confusion, fatigue, or missed opportunities to benefit from synergies in preparedness strategies. A regional interaction framework provides professionals responsible for public education and preparedness with a comprehensive list of possible hazards and a tool through which scenarios of multi-hazard interactions can be identified and discussed with those at risk. The regional interaction framework matrices provide a visualisation tool for more effective discussions and communications with these at-risk communities. When sharing household or individual preparedness steps that could help with reducing vulnerability to one hazard, additional consideration can be given to make sure that they do not increase vulnerability to other hazards.

Failing to consider multi-hazard interactions can therefore lead to the distortion of management priorities, increased vulnerability to other spatially relevant hazards, overwhelm- ing a community with multiple and sometimes conflicting hazard management strategies for multiple hazards, or an overall underestimation of risk (Tobin and Montz, 1997; ARMONIA, 2007; Kappes et al., 2010; Budimir et al., 2014; Mignan et al., 2014; Gill and Malamud, 2014). Regional interaction frameworks are a valuable informational compilation and visualisation tool for (i) raising awareness of the complexities of the multi-hazard environment and (ii) extracting and discussing potential scenarios of multi-hazard interaction networks to explore how exposure and vulnerability may change between successive hazard events.

\subsection{Using regional interaction frameworks to enhance awareness of multi-hazard interactions}

Hazard interactions cut across multiple disciplines and so require input from diverse specialisms (Kappes et al., 2012; Scolobig et al., 2017). Interaction frameworks could therefore help with facilitating enhanced cross-institutional dialogue about hazard interactions and their likelihoods and potential impacts. This could help with strengthening collective knowledge of hazard interactions and the ability of an individual to access this knowledge. By contrasting results from our workshop (Fig. 2) with our Guatemala national interaction framework (Fig. 3), we can examine and quantify congruence between the two matrices and create a new figure. Figure 7 is a $21 \times 21$ interaction matrix that combines Figs. 2 and 3 to indicate the number of workshop participants (from a total of 16) that identified an interaction as being relevant to Guatemala (numbers) and the interactions identified within our national interaction framework (grey shading; from Fig. 3).

Figure 7 combines information and knowledge from 16 participants to present something that is "owned" by no individual. It is collective knowledge, combining information and knowledge owned by multiple people (Antonelli, 2000). We do not expect an individual scientist or hazard professional to map out all relevant interactions. Assessing how an organisation rather than an individual understands interactions demonstrates their collective knowledge. For this knowledge to be truly collective, there must be effective communication between participants and a means by which this knowledge can be accessed, shared, and applied (Foray, 2000; Antonelli, 2000; Paton et al., 2008).

Multi-hazard research is complex and requires scientists and professionals operating in many different disciplines. Figure 7 demonstrates large variation in perspectives between participants on hazard interactions. There is a unanimous consensus (i.e. 16 participants) that an interaction exists in $2(0.5 \%)$ of 441 possible triggering interactions. To assess congruence between the participants' perspectives (numbers in Fig. 7) and national interaction framework (grey shading in Fig. 7), we use Matthews' correlation coefficient, or MCC (Matthews, 1975). MCC values are a function of true positives (TPs), true negatives (TNs), false positives (FPs), 


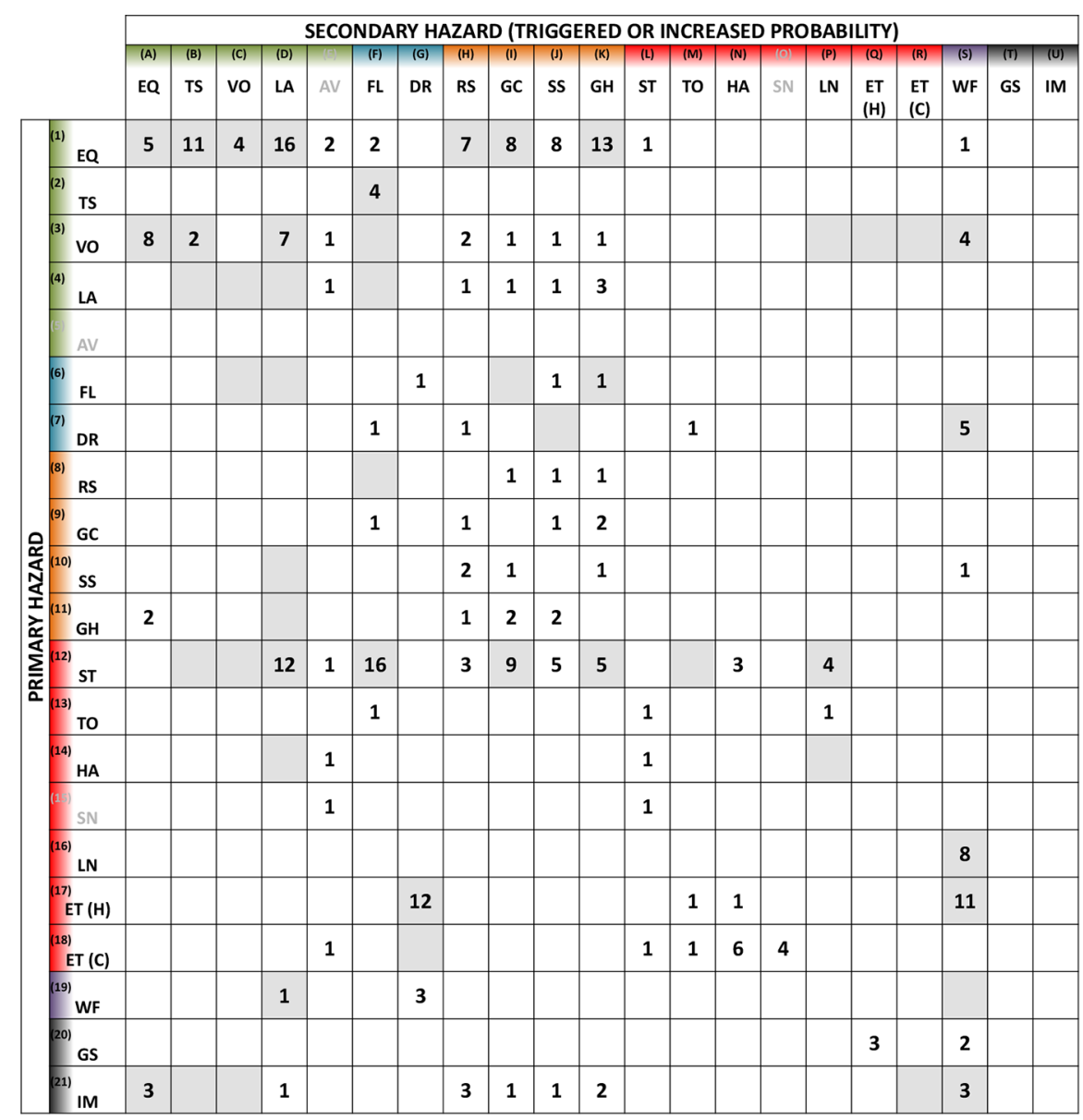

\begin{tabular}{|c|c|c|}
\hline \multicolumn{3}{|c|}{$\begin{array}{c}\text { Regional interaction framework } \\
\text { Guatemala (national) }\end{array}$} \\
\hline \multicolumn{3}{|c|}{ KEY } \\
\hline HAZARD GROUP & HAZARD & CODE \\
\hline \multirow{5}{*}{ GEOPHYSICAL } & Earthquake & EQ \\
\hline & \begin{tabular}{|l|} 
Tsunami \\
\end{tabular} & TS \\
\hline & Volcanic eruption & Vo \\
\hline & Landslide & LA \\
\hline & Snow avalanche (not relevant) & AV \\
\hline \multirow{2}{*}{ HYDROLOGICAL } & Flood & $\mathrm{FL}$ \\
\hline & Drought & $\mathrm{DR}$ \\
\hline \multirow{4}{*}{$\begin{array}{l}\text { SHALLOW } \\
\text { EARTH } \\
\text { PROCESSES }\end{array}$} & Regional subsidence & RS \\
\hline & Ground collapse & GC \\
\hline & Soil (local) subsidence & SS \\
\hline & Ground heave & GH \\
\hline \multirow{7}{*}{ ATMOSPHERIC } & Storm & ST \\
\hline & Tornado & TO \\
\hline & Hailstorm & HA \\
\hline & Snowstorm (not relevant) & SN \\
\hline & Lightning & LN \\
\hline & \begin{tabular}{|l} 
Extreme temperature (hot) \\
\end{tabular} & ET (H) \\
\hline & Extreme temperature (cold) & ET (C) \\
\hline BIOPHYSICAL & Wildfire & WF \\
\hline \multirow{2}{*}{ SPACE } & Geomagnetic storm & GS \\
\hline & Impact event & IM \\
\hline
\end{tabular}

Footnotes: [1B, 4B] Earthquakes and landslides may trigger marine and/or freshwater (lake) tsunamis. [1C,H; 12M] There was uncertainty about the nature of these relationships. [1I,K] Earthquakes may trigger collapse or heave primarily through liquefaction. [3B] Volcanic explosions may trigger freshwater tsunamis in the lakes of Guatemala. [3Q/R] Volcanic eruptions can trigger temperature changes if they are of sufficient magnitude. [6,12C] Water input triggers or increases the probability of a phreatic or phreatomagmatic eruption. [8F] Although regional subsidence triggering flooding was not noted in any evidence source consulted, this is an inevitable consequence of the lowering of the ground surface. [12B] Pressure changes associated with storms may trigger meteotsunamis in marine environments. [21A-C,R,S] Identified as being generally possible, supported by globally relevant literature rather than location-specific evidence.

Figure 7. Stakeholder identification of possible natural-hazard interactions in Guatemala, overlain over the national interaction framework developed in Fig. 3. A $21 \times 21$ matrix with primary natural hazards on the vertical axis and the same natural hazards presented as secondary hazards on the horizontal axis. These hazards are coded, as explained in the key. These matrices show cases where a primary hazard could trigger and/or increase the probability of a secondary hazard. Grey cell shading indicates the interaction and was identified in the national hazard interaction matrix presented in Fig. 3. Numbers indicate the total number (from a maximum of 16) of stakeholders proposing each hazard interaction as being possible in Guatemala.

and false negatives (FNs) and can be expressed as follows (Matthews, 1975; Powers, 2011):

$\mathrm{MCC}=\frac{(\mathrm{TP} \times \mathrm{TN})-(\mathrm{FP} \times \mathrm{FN})}{\sqrt{(\mathrm{TP}+\mathrm{FP})(\mathrm{TP}+\mathrm{FN})(\mathrm{TN}+\mathrm{FP})(\mathrm{TN}+\mathrm{FN})}}$.

The MCC gives a value of congruence between -1.0 (zero overlap between the numbers and grey shading in Fig. 7) and +1.0 (perfect overlap between the numbers and grey shading in Fig. 7). $\mathrm{MCC}=0.0$ suggests that the amount of congruence is no better than a random average (Kaufmann et al., 2012). We use two different approaches: i. All identified interactions. Where $\geq 1$ people note an interaction to be relevant, we consider this to be part of the group's collective knowledge. From Fig. 7, a total of 86 interactions were identified by the 16 workshop participants. This is compared to 50 interactions in the national framework (Fig. 3).

ii. Interactions identified by $\geq x$ participants. A threshold could be applied in terms of the number of participants identifying a given natural-hazard interaction. Only those interactions that reach or exceed this threshold are considered. We select thresholds of $\geq 3$ and $\geq 5$ participants (out of 16 workshop participants) iden- 
Table 7. Calculation of Matthews' correlation coefficient (MCC) to assess agreement between the collective knowledge of 16 workshop participants (Fig. 2) and national interaction framework (Fig. 3). Three different thresholds, each relating to the number of workshop participants (out of 16) identifying a particular interaction, are used to determine collective knowledge of hazard interactions. The number of "agreements" and "disagreements" between the workshop participants' response and national interaction framework (see column headers for descriptions) is shown. For each row, the sum of true positives (TPs) and false negatives (FNs) is 50, and the sum of true negatives (TNs) and false positives (FPs) is 392. MCC values are determined using Eq. (1). MCC $=+1.0$ means complete agreement; MCC $=-1.0$ means complete disagreement.

\begin{tabular}{|c|c|c|c|c|c|c|}
\hline \multirow{3}{*}{$\begin{array}{l}\text { Workshop } \\
\text { participants } \\
\text { identifying an } \\
\text { interaction } \\
(n=16)\end{array}$} & \multirow[t]{3}{*}{$\begin{array}{l}\text { No. interactions } \\
\text { identified by } \\
\geq x \text { participants } \\
\quad(\mathrm{TP}+\mathrm{FP})\end{array}$} & \multicolumn{2}{|c|}{$\begin{array}{c}\text { Agreement } \\
\text { (participants' collective } \\
\text { framework and national } \\
\text { interaction framework agree) }\end{array}$} & \multicolumn{2}{|c|}{$\begin{array}{l}\text { Disagreement } \\
\text { (participants' collective framework } \\
\text { and national interaction framework } \\
\text { do not agree) }\end{array}$} & \multirow[t]{3}{*}{$\begin{array}{c}\text { Matthews } \\
\text { correlation } \\
\text { coefficien } \\
\text { (Eq. 1) }\end{array}$} \\
\hline & & $\begin{array}{l}\text { Interaction } \\
\text { occurs in both } \\
\text { frameworks }\end{array}$ & $\begin{array}{l}\text { Interaction } \\
\text { does not } \\
\text { occur in either } \\
\text { framework }\end{array}$ & $\begin{array}{c}\text { Interaction } \\
\text { occurs in } \\
\text { national } \\
\text { framework but } \\
\text { not participants' } \\
\text { collective } \\
\text { framework }\end{array}$ & $\begin{array}{r}\text { Interaction } \\
\text { occurs in } \\
\text { participants' } \\
\text { collective } \\
\text { framework but } \\
\text { not national } \\
\text { framework }\end{array}$ & \\
\hline & & $\begin{array}{c}\text { True } \\
\text { positives } \\
\text { (TPs) }\end{array}$ & $\begin{array}{c}\text { True } \\
\text { negatives } \\
\text { (TNs) }\end{array}$ & $\begin{array}{c}\text { False } \\
\text { negatives } \\
(\mathrm{FNs})\end{array}$ & $\begin{array}{r}\text { False } \\
\text { positives } \\
(\text { FPs })\end{array}$ & \\
\hline$\geq 1$ & 86 & 25 & 330 & 25 & 61 & 0.28 \\
\hline$\geq 3$ & 32 & 22 & 381 & 28 & 10 & 0.51 \\
\hline$\geq 5$ & 19 & 16 & 388 & 34 & 3 & 0.49 \\
\hline
\end{tabular}

tifying an interaction as being relevant. From Fig. 7, the number of possible interactions identified were 32 (for $\geq 3$ participants) and 19 (for $\geq 5$ participants). These thresholds demonstrate a method for considering what constitutes collective knowledge, but others could be selected.

For these three thresholds $(\geq 1, \geq 3$, and $\geq 5$ participants), we calculate the MCC using Eq. (1). These thresholds are selected arbitrarily to demonstrate how this approach could be adjusted to remove those interactions only volunteered by one professional (or a small number of professionals), thus acting as a form of quality control. Other thresholds could be used. Coefficients for thresholds $\geq 1, \geq 3$, and $\geq 5$ participants are presented in Table 7 and are MCC $=0.28$ when all interactions are considered ( $\geq 1$ participant noting an interaction), improving to $\mathrm{MCC}=0.51$ with a threshold of $\geq 3$ participants and MCC $=0.49$ with a threshold of $\geq 5$ participants. Applying a threshold of $\geq 3$ (vs. $\geq 1$ ) participants identifying an interaction has a slight influence on the number of true positives ( 22 vs. 24 interactions) but significantly reduces the number of false positives ( 10 vs. 62 interactions). Using a sensitivity test, where the number of TPs and TNs are varied by +1 , the MCC changes by 0.02 for each additional TP and 0.01 for each additional TN. For example, a participant identifying 12 TPs and 374 TNs will have MCC $=0.25$, whereas a participant identifying 13 TPs and $375 \mathrm{TNs}$ will have an MCC of 0.28 (i.e. $=0.25+0.01+0.02$ ).
Matthews' correlation coefficient is a simple indicator of agreement, which we use to examine differences between stakeholder perspectives and our national interaction framework (Fig. 3). When applying a small threshold ( $\geq 3$ participants agreeing on a given interaction) to determine which interactions were analysed, the collective knowledge of 16 participants generated the closest agreement to the national interaction framework $(\mathrm{MCC}=0.51)$. This $\mathrm{MCC}$ is based on $22(44 \%)$ of 50 interactions in Fig. 3, being identified by $\geq 3$ participants and therefore $28(56 \%)$ of 50 interactions that $\leq 2$ participants identified in the workshop. Of these 27 interactions identified by $\leq 2$ participants, nobody identified 25 different interactions. These results suggest the following:

- Enhanced communication within and across organisations involved in natural hazards and DRR in Guatemala could help when considering hazard interactions. When co-created by diverse stakeholders, interaction frameworks can help with facilitating communication across specialisms engaged in hazard monitoring and civilprotection. Interaction frameworks could also help elicit additional information for characterising interactions, such as which are most likely to occur and which could cause the greatest damage to interaction likelihoods and impacts. Ensuring that collective understanding of hazard interactions is operationalised to greatest effect will require strong institutions and cross-departmental 
and cross-disciplinary communication (Scolobig et al., 2017).

- National and sub-national interaction frameworks could promote dialogue on both high- and low-likelihood events. Interactions in the national interaction framework (Fig. 3) include some low-likelihood hazard interactions, such as impact events triggering tsunamis and storms triggering meteotsunamis. Workshop participants may not consider low-likelihood events due to lack of access to peer-reviewed literature. Only 5 of the 21 interview participants (Sect. 2.5) had access to, or regularly used, peer-reviewed journals. Interview participants predominantly relied on experience and communication with colleagues for further information on natural hazards and interactions.

- We can use MCC values to monitor changing awareness and perceptions of natural-hazard interactions. MCC values can be determined before interaction frameworks are introduced into an organisation and then recalculated weeks, months, or years after individuals have explored, discussed, and used them in their work.

The results of this exercise demonstrate that there are knowledge gaps that the development of comprehensive and evidenced frameworks of interactions could help address and provide a tool that could help with monitoring changes in awareness of hazard interactions over time.

\subsection{Future research and practice to enhance regional interaction frameworks}

We lay out an approach in Sects. 1 to 3 that integrates diverse evidence sources from the natural and social sciences through a visual database to give a comprehensive, systematic, and evidenced review of the multi-hazard interactions for a regional spatial extent. We believe that this approach builds on and enhances existing forms of regional interaction framework, such as those described in Table 1. Additional research can further enhance regional interaction frameworks (Sect. 4.3.1), as can better understanding how to embed research outputs into relevant agencies through meaningful stakeholder dialogue (Sect. 4.3.2). Engagement with hazard and civil-protection professionals, academics, the private sector, and intergovernmental organisations in Guatemala informed our development of regional interaction frameworks. Understanding stakeholder requirements (e.g. terminology, spatial scales, and temporal scales) helps to ensure that frameworks are fit for purpose. Draft results were discussed with many of these stakeholders in Guatemala in 2018, prior to publishing. We shared our interaction frameworks through seminars, roundtable discussions, and interviews to document perspectives on (i) the structure and content of the interaction frameworks, (ii) use of the interaction frameworks, and (iii) future research and innovation oppor- tunities. We highlight some of the common themes in the following two sub-sections.

\subsubsection{Future research directions}

Three broad areas where additional research could help with enhancing regional interaction frameworks include (i) expanding the range of interaction types considered, (ii) increasing the number of layers within regional interaction frameworks to better characterise interactions, and (iii) quantifying more complex scenarios derived from regional interaction frameworks.

In the regional interaction frameworks we have developed, we have particularly focused on triggering and increased probability interaction types and the way in which these can connect to form multi-hazard interaction network events (cascades). Other interaction types are also important and emphasised in the Sendai Framework, notably where hazardous events occur simultaneously or cumulatively over time. Additional literature searches, fieldwork, data interrogation, and/or stakeholder engagement could be used to document particular physical and social impacts of two or more independent hazards occurring simultaneously or consecutively in a region of interest (e.g. the near-simultaneous eruption of Pacaya volcano and Tropical Storm Agatha in Guatemala in 2010). Examining the impacts of simultaneous or consecutive events on physical infrastructure, response systems, and community well-being could identify particular strengths or weaknesses where investment or capacity strengthening could help with reducing vulnerability to the broad multi-hazard landscape (de Ruiter et al., 2018).

A second stream of research that could enhance regional interaction frameworks is the development and inclusion of additional layers of information such as how often each interaction occurs, possible thresholds, and likelihoods and scales of impact. For each interaction, understanding the frequency-magnitude of occurrence and the range of potential impacts would involve the collation of additional and extensive evidence. We previously noted that some of this information could be elicited from diverse stakeholders, including through forensic studies of past and ongoing disasters, to generate new insights into potential impacts. A "multi-hazard observatory" could also enable the collection of diverse data to better characterise these layers of information. Information for characterising multi-hazard interactions would help with informing decision-making about which interactions primarily need to be addressed to reduce disaster risk.

Building on the enhanced characterisation of potential interactions outlined above, a third stream of research is the quantification of more complex scenarios (interaction network events or cascades) derived from regional interaction frameworks. There is a gap for more modelling of real multihazard situations, involving multiple natural-hazard types, anthropogenic processes, and a range of interaction types. A review of multi-hazard literature completed by Ciurean 
et al. (2018) highlighted that much of the current literature described simulated environments for a limited number of hazard and interaction types. This is potentially due to challenges in access to the data needed to characterise these complex multi-hazard environments and the need to integrate data from different disciplines. One approach to collate relevant data and improve the characterisation of hazard interactions is to use an online wiki-style system where relevant papers, datasets, and assessments of frequency-magnitude can be uploaded.

Furthermore, interaction frameworks can also be used as a tool to guide future research priorities by determining where there is a lack of evidence and/or understanding of certain interactions. For example, in the context of the frameworks developed in Sect. 3 for Guatemala, there were conflicting statements by stakeholders about the potential for both seismic and landslide-triggered tsunamis in the Pacific Ocean and lake systems. Further research about the history and impact of hazards in Central America could therefore be suggested as a priority to better inform the regional interaction framework.

\subsubsection{Embedding and enhancing regional interaction frameworks through stakeholder dialogue}

Embedding regional interaction frameworks into key agencies responsible for hazard monitoring, disaster risk reduction, and disaster response can contribute to improved decision-making by having a more holistic understanding of the multi-hazard landscape. Interaction frameworks are a visual synthesis of diverse knowledge, traditionally owned by diverse disciplinary groups. They can help with enhancing awareness of the spectrum of hazards and hazard interactions in a given territory and strengthen communication across disciplinary boundaries. Interaction frameworks allow those undertaking research into any particular single hazard to place their work within the context of other natural hazards, thus fostering communication between hazard specialists and encouraging a more interdisciplinary approach. When reviewing the draft regional interaction frameworks for Guatemala, one interview participant noted that (translated from Spanish) "sometimes knowledge is in a head, but now it is in a visual summary [that can be used by a range of people]".

One future step to help embed regional interaction frameworks into decision-making is to consider the scale of the spatial extent for which they are prepared. Many participants suggested that municipalities are the preferred scale of interest for further multi-hazard tools. Guatemala currently has 340 municipalities across 22 departments. The emphasis on municipalities likely arises from the political context in Guatemala, with municipal authorities being the final users of information. Other stakeholders noted that it may not be most effective (or efficient) to produce municipal-scale hazard assessments as hazards cross municipal, departmental, and national boundaries. Tools can therefore be prepared at scales that both provide useful information to those working at a municipal scale and recognise the artificial nature of these boundaries. Tools that allow the spatial representation of information in Sect. 3 could facilitate this, seeing both municipal perspectives and cross-border challenges. A GIS tool allowing the creation of municipal multi-hazard risk maps was a high priority of stakeholders, allowing the identification of hazard hotspots, improved disaster preparation (e.g. evacuation routes), and enhanced response through improved communication of potential secondary hazards. Spatial representation of information could help with identifying regions where secondary hazards are more likely after a primary hazard and the assessment of disaster impacts, including those generated through secondary hazards, by overlay of exposure and multi-hazard maps.

Participants also noted specific ways in which they could use regional interaction frameworks in their ongoing work. INSIVUMEH, CONRED, and UN-OCHA indicated that they could use interaction frameworks as reference tools to strengthen preparedness and response to hazards. CONRED suggested they could integrate secondary hazards information into their public information bulletins and requested blank matrices to complete for specific high-risk municipalities. Finally, universities indicated that they would use this research and our systematic classification of hazards in Guatemala in their teaching. Fully realising the impact of regional interaction frameworks, and ensuring positive social impact, will require sustained collaborative engagement with user communities. The potential developments and applications outlined through Sect. 4.3 would support the embedding and operationalisation of this research in Guatemala with the lessons learned helping other regions and the wider hazard or disaster risk community.

\section{Conclusions}

Understanding and characterising the multi-hazard landscape of a region directly support the implementation of the Sendai Framework (UNDRR, 2015). In this paper, we have addressed three research questions, originally outlined in Sect. 1:

- For a defined spatial region, how does one construct and populate a synthesis of all relevant potential naturalhazard interactions using blended sources of evidence for past case histories and theoretical future possibilities from that region's characteristics?

- How do triggering interactions documented in the literature contrast with the knowledge of hazard or civilprotection professionals operating in the region?

- What are the implications of our regional interaction frameworks for multi-hazard methodologies to support disaster risk reduction, management, and response? 
We develop and describe an approach for understanding the multi-hazard landscape through comprehensive, systematic, and evidenced regional interaction frameworks. We apply this approach in Guatemala, generating regional interaction frameworks for the national spatial extent of Guatemala and sub-national spatial extent of the southern Guatemalan Highlands. Five evidence types (internationally accessible publications and reports, locally accessible civil-protection bulletins, field observations, semi-structured stakeholder interviews, and a stakeholder workshop) underpin the construction and population of these frameworks. We use this evidence to do the following:

i. Determine an appropriate classification scheme. For Guatemala, this consists of six natural-hazard groups, 19 hazard types, and 37 hazard sub-types.

ii. Identify potential natural-hazard interactions. For a national spatial extent in Guatemala, we identify 50 possible interactions between 16 relevant primary naturalhazard types and 15 relevant secondary hazard types. For the southern Guatemalan Highlands, we identify 114 possible interactions between 33 relevant naturalhazard sub-types.

Interaction frameworks can help with improving understanding of the multi-hazard landscape of a given region and potential scenarios of multi-hazard interaction network events (cascades). We present information in accessible visualisations, primarily with interaction matrices. The use of accessible visualisation tools, such as matrices, to represent complex hazard interactions contributes to knowledge exchange across different disciplines. We demonstrate through Matthews' correlation coefficient, a simple indicator of agreement, that there are many differences between stakeholder perspectives and our national interaction framework. The development of comprehensive and evidenced frameworks of interactions could help with increasing awareness of multi-hazard interactions and strengthening communication between different stakeholders to improve collective knowledge. They could also be used as a tool to monitor changes in understanding of hazard interactions over time.

Our approach allows those working on any individual hazard in Guatemala to place their work within the context of other natural hazards. When taking drafts of regional interaction frameworks back to Guatemala government hazard scientists and technicians in 2018, we observed them fostering communication between hazard specialists and encouraging integrated multi-hazard approaches to DRR. We believe that our approach is scalable and can be replicated in diverse geographical settings. While examples of regional interaction frameworks exist in the literature, these often do not include a systematic assessment of possible natural hazards and interactions for a defined spatial extent.

By integrating diverse evidence types, we have developed an approach that constrains relevant interactions between a comprehensive selection of natural hazards, simplifying a broad array of complex information to facilitate an effective analysis by those working on reducing and managing the risk from natural hazards within both policy and practitioner sectors. We believe that our approach can support the scientific community in constructing more evidenced and detailed profiles of relevant interactions for diverse user groups, identifying and exploring multi-hazard interaction scenarios and how they may result in changes to exposure and vulnerability (potentially exacerbating risk), and extracting locally specific research and innovation gaps.

Data availability. Underlying data used in this research are laid out in Sect. 2, with further information in the Supplement. This includes existing published literature, civil protection bulletins, field observations, stakeholder interviews, and focus groups.

Supplement. The supplement related to this article is available online at: https://doi.org/10.5194/nhess-20-149-2020-supplement.

Author contributions. JCG and BDM designed and conducted research, including in-depth discussions with EMB and AGN during data collection. All co-authors analysed results and their implications to disaster risk reduction in the region. JCG wrote the paper, with major contributions from BDM and further input from all coauthors.

Competing interests. Joel C. Gill, Edy Manolo Barillas, and Alex Guerra Noriega declare that they have no conflict of interest. Bruce D. Malamud is a member of the editorial board of the journal.

Acknowledgements. We are grateful to staff at INSIVUMEH, CONRED, and Universidad de San Carlos de Guatemala for their engagement with our work. We are particularly thankful to Gustavo Chigna (INSIVUMEH) for his sustained advice and support in the field while in Guatemala. We thank Roxana Ciurean, Christian Huggel, and Kirsten v. Elverfeldt for their constructive reviews. This article is published with the permission of the Executive Director, British Geological Survey (UKRI).

Financial support. The lead author initiated this work, while a $\mathrm{PhD}$ candidate in the Department of Geography, King's College London, with funding from a NERC/ESRC studentship (grant no. NE/J500306/1). Subsequent engagement in Guatemala was funded by the British Geological Survey Innovation Flexible Fund and supported by BGS NC-ODA (grant no. NE/R000069/1): Geoscience for Sustainable Futures.

Review statement. This paper was edited by Sven Fuchs and reviewed by Kirsten v. Elverfeldt and Christian Huggel. 


\section{References}

Alvarado, G. E., Soto, G. J., Pullinger, C. R., Escobar, R., Bonis, S., Escobar, D., and Navarro, M.: Volcanic Activity, Hazards and Monitoring, in: Central America, Two Volume Set: Geology, Resources and Hazards, edited by: Bundschuh, J. and Alvarado, G. E., Taylor and Francis, London, UK, 1155-1188, 2007.

Antonelli, C.: Collective knowledge communication and innovation: the evidence of technological districts, Reg. Stud., 34, 535547, https://doi.org/10.1080/00343400050085657, 2000.

ARMONIA - Applied multi Risk Mapping of Natural Hazards for Impact Assessment: Assessing and mapping multiple risks for spatial planning, European Union 6th Framework Programme Reports, European Union, available at: https://forum.eionet.europa.eu/nrc-air-climate/library/public/ 2010_citiesproject/interchange/armonia_project (last access: 9 December 2019), 2007.

Bommer, J. J. and Rodríguez, C. E.: Earthquake-induced landslides in Central America, Eng. Geol., 63, 189-220, https://doi.org/10.1016/S0013-7952(01)00081-3, 2002.

Brown, S. K., Sparks, R. S. J., Mee, K., Vye-Brown, C., Ilyinskaya, E., Jenkins, S. F., and Loughlin, S. C.: Country and regional profiles of volcanic hazard and risk (Appendix B), in: Global Volcanic Hazards and Risk, edited by: Loughlin, S. C., Sparks, R. S. J., Brown, S. K., Jenkins, S. F., and Vye-Brown, C., Cambridge University Press, Cambridge, https://doi.org/10.1017/CBO9781316276273.030, 2015.

Bucknam, R. C., Coe, J. A., Chavarría, M. M., Godt, J. W., Tarr, A. C., Bradley, L. A., Rafferty, S., Hancock, D., Dart, R. L., and Johnson, M. L.: Landslides triggered by hurricane Mitch in Guatemala: Inventory and discussion, US Geological Survey Open File Report 01-443, US Department of the Interior, USA, p. 38, 2001.

Budimir, M. E. A., Atkinson, P. M., and Lewis, H. G.: Earthquakeand-landslide events are associated with more fatalities than earthquakes alone, Nat. Hazards, 72, 895-914, 2014.

Bündnis Entwicklung Hilft/United Nations University: World Risk Report 2017, Bündnis Entwicklung Hilft, Berlin, p. 48, 2017.

Bundschuh, J. and Alvarado, G. E. (Eds.): Central America Geology, Resources and Hazards (Two Volume Set), Taylor and Francis, London, UK, p. 1131, 2007.

Cahoon, D. R. and Hensel, P.: Hurricane Mitch: a regional perspective on mangrove damage, recovery and sustainability, USGS Open File Report 03-183, US Geological Survey, USA, p. 31, 2002

Carrara, A., Crosta, G., and Frattini, P.: Geomorphological and historical data in assessing landslide hazard, Earth Surf. Proc. Land., 28, 1125-1142, https://doi.org/10.1002/esp.545, 2003.

Charvériat, C.: Natural Disasters in Latin America and the Caribbean: An Overview of Risk, Working Paper, InterAmerican Development Bank, Research Department, No. 364, available at: http://papers.ssrn.com/sol3/papers.cfm?abstractid= 1817233 (last access: 29 November 2018), 2000.

Choine, M. N., O’Connor, A., Gehl, P., D’Ayala, D., GarcíaFernández, M., Jiménez, M. J., Gavin, K., Van Gelder, P., Salceda, T., and Power, R.: A multi hazard risk assessment methodology accounting for cascading hazard events, in: 12th International Conference on Applications of Statistics and Probability in Civil Engineering, ICASP12, 12-15 July 2015, Vancouver, Canada, available at: https://open.library.ubc.ca/cIRcle/ collections/53032/items/1.0076192 (last access: 29 November 2018), 2015.

CIA - Central Intelligence Agency: Guatemala Physiography, available at: https://www.cia.gov/library/publications/resources/ cia-maps-publications/Guatemala.html (last access: 29 November 2018), 2001.

Ciurean, R., Gill, J. C., Reeves, H., O’Grady, S. K., Donald, K., and Aldridge, T.: Review of multi-hazards research and risk assessments, British Geological Survey Engineering Geology \& Infrastructure Programme, Open Report OR/18/057, British Geological Survey, UK, 2018.

Claxton, R. H.: Weather-based Hazards in Colonial Guatemala, Stud. Social Sci., 25, 139-163, 1986.

CONRED - Coordinadora Nacional para la Reducción de Desastres: home page, available at: https://conred.gob.gt/site/index.php (last access: 29 November 2018), 2018a.

CONRED - Coordinadora Nacional para la Reducción de Desastres: Boletínes Informativos, available at: https://conred.gob.gt/ site/Boletines-Informativos (last access: 19 November 2018), 2018b.

Cooper, A. H. and Calow, R. C.: Avoiding gypsum geohazards: guidance for planning and construction, British Geological Survey, Technical Report WC/98/5, UK NG125GG, available at: http://nora.nerc.ac.uk/14146/1/Cooper_Callow_1998_ DIFID_Gypsum_and_planning_WC_98_005_COL.pdf (last access: 29 November 2018), 1998.

CRED - Centre for Research on the Epidemiology of Disasters: EM-DAT: The International Disaster Database, available at: https://www.emdat.be/database, last access: 29 November 2018.

De Pippo, T., Donadio, C., Pennetta, M., Petrosino, C., Terlizzi, F., and Valente, A.: Coastal hazard assessment and mapping in Northern Campania, Italy, Geomorphology, 97, 451-466, https://doi.org/10.1016/j.geomorph.2007.08.015, 2008.

de Ruiter, M. C., Couasnon, A., van den Homberg, M., Ward, P., and Daniell, J. E.: How Do Consecutive Disasters Affect Damages and the Post-Disaster Recovery Process?, in: AGU Fall Meeting Abstracts, 10-14 December 2018, Washington, D.C., USA, December 2018.

DesInventar: Guatemala, available at: http://www.desinventar.net/ DesInventar/profiletab.jsp\#more_info (last access: 29 November 2018), 2016.

DiCicco-Bloom, B. and Crabtree, B. F.: The qualitative research interview, Medical Educ., 40, 314-321, https://doi.org/10.1111/j.1365-2929.2006.02418.x, 2006.

Duncan, M., Edwards, S., Kilburn, C., and Twigg, J.: An interrelated hazards approach to anticipating evolving risk, in: The Making of a Riskier Future: How Our Decisions Are Shaping Future Disaster Risk, Global Facility, GFDRR, Washington, D.C., USA, 2016.

Ebmeier, S. K., Biggs, J., Mather, T. A., Elliott, J. R., Wadge, G., and Amelung, F.: Measuring large topographic change with InSAR: Lava thicknesses, extrusion rate and subsidence rate at Santiaguito volcano, Guatemala, Earth Planet. Sc. Lett., 335, 216-225, https://doi.org/10.1016/j.eps1.2012.04.027, 2012.

Edwards, R.: A critical examination of the use of interpreters in the qualitative research process, J. Ethnic Migrat. Stud., 24, 197208, https://doi.org/10.1080/1369183X.1998.9976626, 1998. 
Espinosa, A. F. (Ed.): The Guatemalan earthquake of February 4, 1976: A preliminary report, US Geological Survey Professional Paper 1002, US Government Printing Office, USA, 1976.

Fernández, M. and Ortiz, M.: Earthquake triggered tsunamis, in: Central America, Two Volume Set: Geology, Resources and Hazards, edited by: Bundschuh, J. and Alvarado, G. E., Taylor and Francis, London, UK, 1257-1265, 2007.

Fisher, K. T.: Positionality, subjectivity, and race in transnational and transcultural geographical research, Gender Place Cult., 22, 456-473, https://doi.org/10.1080/0966369X.2013.879097, 2015.

Foray, D.: Characterising the knowledge base: available and missing indicators, in: Knowledge management in the learning society, OECD, Paris, France, 239-255, 2000.

Gill, J. C.: Increasing the Understanding and Characterisation of Natural Hazard Interactions, Doctoral Thesis, King's College, London, 2016.

Gill, J. C. and Malamud, B. D.: Reviewing and visualizing the interactions of natural hazards, Rev. Geophys., 52, 680-722, 2014.

Gill, J. C. and Malamud, B. D.: Hazard interactions and interaction networks (cascades) within multi-hazard methodologies, Earth Syst. Dynam., 7, 659-679, https://doi.org/10.5194/esd-7659-2016, 2016.

Gill, J. C., and Malamud, B. D.: Anthropogenic processes, natural hazards, and interactions in a multi-hazard framework, Earth-Sci. Rev., 166, 246-269, 2017.

Glade, T.: Landslide occurrence as a response to land use change: a review of evidence from New Zealand, Catena, 51, 297-314, https://doi.org/10.1016/S0341-8162(02)00170-4, 2003.

Global Volcanism Program: Volcanoes of the World, available at: http://volcano.si.edu/ (last access: 29 November 2018), 2013.

Guzzetti, F., Cardinali, M., and Reichenbach, P.: The AVI project: a bibliographical and archive inventory of landslides and floods in Italy, Environ. Manage., 18, 623-633, https://doi.org/10.1007/BF02400865, 1994.

Han, J., Wu, S., and Wang, H.: Preliminary study on geological hazard chains, Earth Sci. Front., 14, 11-20, https://doi.org/10.1016/S1872-5791(08)60001-9, 2007.

Harp, E. L., Wilson, R. C., and Wieczorek, G. F.: Landslides from the February 4, 1976, Guatemala earthquake, US Geological Survey Professional Paper 1204-A, US Government Printing Office, USA, 1981.

Harris, A. J., Vallance, J. W., Kimberly, P., Rose, W. I., Matías, O., Bunzendahl, E., Flynn, L. P., and Garbeil, H. Downstream aggradation owing to lava dome extrusion and rainfall runoff at Volcan Santiaguito, Guatemala, Geol. Soc. Am. Spec. Pap., 412, 85-104, https://doi.org/10.1130/2006.2412(05), 2006.

Havenith, H.-B., Strom, A., Jongmans, D., Abdrakhmatov, A., Delvaux, D., and Tréfois, P.: Seismic triggering of landslides, Part A: Field evidence from the Northern Tien Shan, Nat. Hazards Earth Syst. Sci., 3, 135-149, https://doi.org/10.5194/nhess3-135-2003, 2003.

Hermosilla, R. G.: The Guatemala City sinkhole collapses, Carbon. Evapor., 27, 103-107, https://doi.org/10.1007/s13146-011-00741,2012

Hodell, D. A., Brenner, M., Curtis, J. H., and Guilderson, T.: Solar forcing of drought frequency in the Maya lowlands, Science, 292, 1367-1370, https://doi.org/10.1126/science.1057759, 2001.
Hunt, R. E.: Geotechnical Engineering Investigation Handbook, CRC Press, Florida, USA, p. 1088, 2005.

Ibsen, M. L. and Brunsden, D.: The nature, use and problems of historical archives for the temporal occurrence of landslides, with specific reference to the south coast of Britain, Ventnor, Isle of Wight, Geomorphology, 15, 241-258, https://doi.org/10.1016/0169-555X(95)00073-E, 1996.

IFFN - International Forest Fire News: Fire Situation in Guatemala, available at: http://www2.fire.uni-freiburg.de/iffn/country/gt/gt_ 1_eng.htm (last access: 29 November 2018), 2002.

INSIVUMEH - Instituto Nacional de Sismología, Vulcanología, Meteorología e Hidrología/National Institute for Seismology, Volcanology, Meteorology and Hydrology: Home page, available at: http://insivumeh.gob.gt/, last access: 29 November 2018.

Johnson, J. B. and Lees, J. M.: Sound produced by the rapidly inflating Santiaguito lava dome, Guatemala, Geophys. Res. Lett., 37, L22305, https://doi.org/10.1029/2010GL045217, 2010.

Johnson, J. B., Lees, J. M., Gerst, A., Sahagian, D., and Varley, N.: Long-period earthquakes and co-eruptive dome inflation seen with particle image velocimetry, Nature, 456, 377-381, https://doi.org/10.1038/nature07429, 2008.

Kappes, M. S., Keiler, M., and Glade, T.: From Single- to MultiHazard Risk Analyses: a concept addressing emerging challenges, in: Mountain Risks: Bringing Science to Society, edited by: Malet, J. P., Glade, T., and Casagli, N., CERG Editions, Strasbourg, France, 351-356, 2010.

Kappes, M. S., Keiler, M., von Elverfeldt, K., and Glade, T.: Challenges of analyzing multi-hazard risk: a review, Nat. Hazards, 64, 1925-1958, 2012.

Kaufmann, O., Deceuster, J., and Quinif, Y.: An electrical resistivity imaging-based strategy to enable sitescale planning over covered palaeokarst features in the Tournaisis area (Belgium), Eng. Geol., 133, 49-65, https://doi.org/10.1016/j.enggeo.2012.01.017, 2012.

Kitchin, R. and Tate, N. J.: Conducting research into human geography, in: Theory, Methodology and Practice, Pearson Education Limited, Harlow, UK, p. 330, 2000.

Knapen, A., Kitutu, M. G., Poesen, J., Breugelmans, W., Deckers, J., and Muwanga, A.: Landslides in a densely populated county at the footslopes of Mount Elgon (Uganda): characteristics and causal factors, Geomorphology, 73, 149-165, https://doi.org/10.1016/j.geomorph.2005.07.004, 2006.

Kreft, S., Eckstein, D., Dorsch, L., and Fischer, L.: Global Climate Risk Index 2016: Who Suffers Most From Extreme Weather Events? Weather-related Loss Events in 2014 and 1995 to 2014, available at: http://germanwatch.org/fr/download/13503.pdf (last access: 29 November 2018), 2015.

Kueny, J. A. and Day, M. J.: Designation of protected karstlands in Central America: a regional assessment, J. Cave Karst Stud., 64, 165-174, 2002.

LAHT - Latin American Herald Tribune: Guatemala to Deliver Food to 170,000 Families Affected by Heatwave, available at: http://www.laht.com/article.asp?ArticleId= 2347276andCategoryId=23558 (last access: 29 November 2018), 2014.

Lindholm, C. D., Climent, A., Camacho, E., Strauch, W., Cepeda, J., Cáceras, D., Ligorría, J. P., and Bungum, H.: Seismic hazard and microzonation, in: Central America, Two Volume Set: Geology, 
Resources and Hazards, edited by: Bundschuh, J. and Alvarado, G. E., Taylor and Francis, London, 1099-1118, 2007.

Liu, B., Siu, Y. L., and Mitchell, G.: Hazard interaction analysis for multi-hazard risk assessment: a systematic classification based on hazard-forming environment, Nat. Hazards Earth Syst. Sci., 16, 629-642, https://doi.org/10.5194/nhess-16-629-2016, 2016.

Longhurst, R.: Semi-structured interviews and focus groups, in: Key Methods in Geography, edited by: Clifford, N. J. and Valentine, G., SAGE Publications, London, 117-132, 2003.

Luna, B.: Assessment and Modeling of two Lahars caused by 'Hurricane Stan' at Atitlan, Guatemala, October 2005, Doctoral dissertation, MSc. Thesis, University of Oslo, Oslo, available at: https://www.duo.uio.no/handle/10852/12448 (last access: 29 November 2018), 2007.

MacDougall, C.,and Fudge, E.: Planning and recruiting the sample for focus groups and in-depth interviews, Qual. Health Res., 11, 117-126, 2001.

Madge, C.: Boundary disputes: comments on Sidaway (1992), Area, 25, 294-299, 1993.

MAGA - Ministerio de Agricultura Ganadería y Alimentación: Frost/Ice Hazard Map, Guatemala, 2002.

MAGA/PEDN - Ministerio de Agricultura Ganadería y Alimentación/Programa de Emergencia por Desastres Naturales: Soil Types Map, Guatemala, 2002a.

MAGA/PEDN - Ministerio de Agricultura Ganadería y Alimentación/Programa de Emergencia por Desastres Naturales: Annual Average Precipitation Map, Guatemala, 2002b.

Mahood, Q., Van Eerd, D., and Irvin, E.: Searching for grey literature for systematic reviews: challenges and benefits, Res. Synthes. Meth., 5, 221-234, 2014.

Matthews, B. W.: Comparison of the predicted and observed secondary structure of T4 phage lysozyme, Biochimica et Biophysica Acta (BBA)-Protein Structure, 405, 442-451, https://doi.org/10.1016/0005-2795(75)90109-9, 1975.

McGuire, B. and Maslin, M. A. (Eds.): Climate Forcing of Geological Hazards, Wiley-Blackwell, West Sussex, UK, p. 311, 2012.

Merriam, S. B., Johnson-Bailey, J., Lee, M. Y., Kee, Y., Ntseane, G., and Muhamad, M.: Power and positionality: Negotiating insider/outsider status within and across cultures, Int. J. Lifelong Educ., 20, 405-416, https://doi.org/10.1080/02601370120490, 2001.

Mignan, A., Wiemer, S., and Giardini, D.: The quantification of low-probability-high-consequences events: Part I. A generic multi-risk approach, Nat. Hazards, 73, 1999-2022, 2014.

Moeller, S. D.: Regarding the Pain of Others: Media, Bias and the Coverage of International Disasters, J. Int. Affairs, 59, 173-196, 2006.

Moreno, A. R.: Climate change and human health in Latin America: drivers, effects, and policies, Reg. Environ. Change, 6, 157-164, https://doi.org/10.1007/s10113-006-0015-z, 2006.

NASA - National Aeronautics and Space Administration: Patterns of Lightning Activity, available at: http: //earthobservatory.nasa.gov/IOTD/view.php?id=6679andeocn= imageandeoci=related_image (last access: 29 November 2018), 2006.

Neri, A., Aspinall, W. P., Cioni, R., Bertagnini, A., Baxter, P. J., Zuccaro, G., Andronico, D., Barsotti, S., Cole, P. D., Espoti-Ongaro, T., Hincks, T. K., Macedonio, G., Papale, P., Rosi, M., Santacroce, R., and Woo, G.: Develop- ing an event tree for probabilistic hazard and risk assessment at Vesuvius, J. Volcanol. Geoth. Res., 178, 397-415, https://doi.org/10.1016/j.jvolgeores.2008.05.014, 2008.

Neri, M., Le Cozannet, G., Thierry, P., Bignami, C., and Ruch, J.: A method for multi-hazard mapping in poorly known volcanic areas: an example from Kanlaon (Philippines), Nat. Hazards Earth Syst. Sci., 13, 1929-1943, https://doi.org/10.5194/nhess13-1929-2013, 2013.

Owen, L. A., Kamp, U., Khattak, G. A., Harp, E. L., Keefer, D. K., and Bauer, M. A.: Landslides triggered by the 8 October 2005 Kashmir earthquake, Geomorphology, 94, 1-9, https://doi.org/10.1016/j.geomorph.2007.04.007, 2008.

Palinkas, L. A., Horwitz, S. M., Green, C. A., Wisdom, J. P., Duan, N., and Hoagwood, K.: Purposeful sampling for qualitative data collection and analysis in mixed method implementation research, in: Administration and Policy in Mental Health and Mental Health Services Research, Vol. 42, Springer, 533544, 2015.

Paton, D., Smith, L., Daly, M., and Johnston, D.: Risk perception and volcanic hazard mitigation: Individual and social perspectives, J. Volcanol. Geoth. Res., 172, 179-188, https://doi.org/10.1016/j.jvolgeores.2007.12.026, 2008.

Pescaroli, G. andAlexander, D.: Understanding compound, interconnected, interacting, and cascading risks: a holistic framework, Risk Anal., 38, 2245-2257, 2018.

Pielke Jr., R. A., Rubiera, J., Landsea, C., Fernández, M. L., and Klein, R.: Hurricane vulnerability in Latin America and the Caribbean: Normalized damage and loss potentials, Nat. Hazards Rev., 4, 101-114, https://doi.org/10.1061/(ASCE)15276988(2003)4:3(101), 2003.

Plafker, G., Bonilla, M. G., and Bonis, S. B.: Geologic Effects, in: The Guatemalan earthquake of February 4, 1976: A preliminary report, edited by: Espinosa, A. F., US Geological Survey Professional Paper 1002, US Government Printing Office, USA, 38-51, 1976.

Porfido, S., Esposito, E., Spiga, E., Sacchi, M., Molisso, F., and Mazzola, S.: Re-evaluation of the 1976 Guatemala earthquake taking into account the environmental effects, in: 11th EGU General Assembly, 27 April-2 May 2014, Vienna, Austria, Geophys. Res. Abstr., 16, EGU2014-6525, 2014.

Porfido, S., Esposito, E., Spiga, E., Sacchi, M., Molisso, F., and Mazzola, S.: Impact of Ground Effects for an Appropriate Mitigation Strategy in Seismic Area: The Example of Guatemala 1976 Earthquake, in: Engineering Geology for Society and Territory-Volume 2 (Landslide Processes), edited by: Lollino, G., Giordan, D., Crosta, G. B., Corominas, J., Azzam, R., Wasowski, J., and Sciarra, N., Springer International Publishing, Switzerland, 703-708, https://doi.org/10.1007/9783-319-09057-3_117, 2015.

Powers, D. M. W.: Evaluation: from Precision, Recall and Fmeasure to ROC, Informedness, Markedness and Correlation, J. Mach. Learn. Technol., 2, 37-63, 2011.

$\mathrm{Qu}$, S. Q. and Dumay, J.: The qualitative research interview, Qual. Res. Account. Manage., 8, 238-264, https://doi.org/10.1108/11766091111162070, 2011.

Raška, P., Zábranský, V., Dubišar, J., Kadlec, A., Hrbáčová, A., and Strnad, T.: Documentary proxies and interdisciplinary research on historic geomorphologic hazards: a discussion of the current 
state from a central European perspective, Nat. Hazards, 70, 705732, https://doi.org/10.1007/s11069-013-0839-z, 2014.

ReliefWeb: Guatemala Boletínes Informativos, available at: http: //reliefweb.int/updates?search=Boletininformativos (last access: 29 November 2018), 2016.

ReliefWeb: Situation Reports for Central America following Tropical Storm Nate, available online: https://reliefweb.int/disaster/ tc-2017-000148-nic/thumb, last access: 29 November 2018.

Rodríguez, C.E.: Earthquake-induced landslides, in: Central America, Two Volume Set: Geology, Resources and Hazards, edited by: Bundschuh, J. and Alvarado, G. E., Taylor and Francis, London, 1217-1255, 2007.

Rose, W. I., Bommer, J. J., Lopez, D. L., Carr, M. J., and Major, J. J. (Eds.): Natural hazards in El Salvador, in: Vol. 375, Geological Society of America, Boulder, Colorado, USA, 2004.

Satarugsa, P.: The Lessons Learnt from Geophysical Investigation of Sinkholes in Rock Salt in Thailand, in: International Conference on Geology, Geotechnology and Mineral Resources of Indochina (GEOINDO 2011), 1-3 December 2011, Khon Kaen, Thailand, available at: http://home. kku.ac.th/peangta/peangta-final-sinkhole2011.pdf (last access: 29 November 2018), 2011.

Schneider, S. C. and Barsoux, J. L.: Managing across cultures, Pearson Education, Harlow, England, p. 352, 2002.

Schuster, R. L., Bucknam, R. C., and Mota, M. A.: Stability assessment of a Hurricane Mitch-induced landslide dam on the Rio La Lima, Sierra de Las Minas, eastern Guatemala, Open File Report 01-120, US Geological Survey, US Department of the Interior, USA, 2001.

Scolobig, A., Nadejda, K., and Arnaud, M.: Mainstreaming MultiRisk Approaches into Policy, Geosciences, 7, 1-18, 2017.

Seed, H. B., Arango, I., Gomez-Masso, A., Ascoli, R. G., and Chan, C.: Earthquake-induced liquefaction near lake Amatitlan, Guatemala, J. Geotech. Geoenviron. Eng., 107, 501-518, 1981.

Siebert, L., Alvarado, G. E., Vallance, J. W., and De Vries, B. V. W.: Large-volume volcanic edifice failures in Central America and associated hazards, Geol. Soc. Am. Spec. Pap., 412, 1-26, https://doi.org/10.1130/2006.2412(01), 2006.

Soto, A. J., Rodhe, A., Pohjola, V., and Boelhouwers, J.: Spatial distribution of disasters caused by natural hazards in the Samala River catchment, Guatemala, Geograf. Ann. A, 97, 181-196, https://doi.org/10.1111/geoa.12097, 2015.

Squires, A.: Methodological challenges in cross-language qualitative research: a research review, Int. J. Nurs. Stud., 46, 277-287, https://doi.org/10.1016/j.ijnurstu.2008.08.006, 2009.

Stewart, S. R.: Eastern North Pacific Hurricanes 2010 Flooding in a Slow Season, Weatherwise, 64, 38-45, https://doi.org/10.1080/00431672.2011.566819, 2011.

Stewart, S. R. and Cangialosi, J. P.: Eastern North Pacific Hurricane Season of 2010, Mon. Weather Rev., 140, 2769-2781, https://doi.org/10.1175/MWR-D-11-00152.1, 2012.

Sultana, F.: Reflexivity, positionality and participatory ethics: Negotiating fieldwork dilemmas in international research, ACME, 6, 374-385, 2007.

Suri, H.: Purposeful sampling in qualitative research synthesis, Qual. Res. J., 11, 63-75, 2011.

Tappin, D. R.: Submarine mass failures as tsunami sources: their climate control, Philos. T. Roy. Soc. Lond. A, 368, 2417-2434, https://doi.org/10.1098/rsta.2010.0079, 2010.
Tarvainen, T., Jarva, J., and Greiving, S.: Spatial pattern of hazards and hazard interactions in Europe, in: Natural and Technological Hazards and Risks Affecting the Spatial Development of European Regions, 42, edited by: Schmidt-Thomé, P., Geological Survey of Finland, Finland, 83-91, 2006.

Taylor, F. E., Malamud, B. D., Freeborough, K., and Demeritt, D.: Enriching Great Britain's National Landslide Database by searching newspaper archives, Geomorphology, 249, 52-68, https://doi.org/10.1016/j.geomorph.2015.05.019, 2015.

Temple, B. and Edwards, R.: Interpreters/translators and crosslanguage research: Reflexivity and border crossings, Int. J. Qual. Meth., 1, 1-12, https://doi.org/10.1177/160940690200100201, 2002.

Temple, B. and Young, A.: Qualitative research and translation dilemmas, Qual. Res., 4, 161-178, https://doi.org/10.1177/1468794104044430, 2004.

Tilloy, A., Malamud, B. D., Winter, H., and Joly-Laugel, A.: A review of quantification methodologies for multihazard interrelationships, Earth-Sci. Rev., 196, 102881, https://doi.org/10.1016/j.earscirev.2019.102881, 2019.

Tobin, G. A. and Montz, B. E.: Natural Hazards: Explanation and Integration, Guilford Press, New York, 1997.

Trimble, S. W.: The use of historical data and artifacts in geomorphology, Prog. Phys. Geogr., 32, 3-29, https://doi.org/10.1177/0309133308089495, 2008.

UNDRR - United Nations Office for Disaster Risk Reduction: Sendai Framework for Disaster Risk Reduction, United Nations, Geneva, p. 37, 2015.

UNDRR - United Nations Office for Disaster Risk Reduction: DRR Terminology, available at: https://www.unisdr.org/we/inform/ terminology (last access: 29 November 2018), 2017.

Valentine, G.: Tell me about... using interviews as a research methodology, in: Methods in human geography: A guide for students doing a research project, edited by: Flowerdew, R. and Martin, D., Prentice Hall, Harlow, UK, 110-126, 1997.

van Westen, C. J., Kappes, M. S., Luna, B. Q., Frigerio, S., Glade, T., and Malet, J.-P.: Medium-scale multi-hazard risk assessment of gravitational processes, in: Mountain risks: from prediction to management and governance, edited by: van Asch, T., Corominas, J., Greiving, S., Malet, J.-P., and Sterlacchini, S., Springer, Dordrecht, the Netherlands, 201-231, https://doi.org/10.1007/978-94-007-6769-0_7, 2014.

von Huene, R., Ranero, C. R., and Watts, P.: Tsunamigenic slope failure along the Middle America Trench in two tectonic settings, Mar. Geol., 203, 303-317, https://doi.org/10.1016/S00253227(03)00312-8, 2004.

Welle, T., Birkmann, J., Rhyner, J., Witting, M., and Wolfertz, J.: World Risk Index 2013, in: World Risk Report 2013, edited by: Jeschonnek, L., Alliance Development Works, Berlin, Germany, 45-56, 2013.

World Bank: Precipitation in Guatemala 1900-2012, available at: http://sdwebx.worldbank.org/climateportal/index. cfm?page=country_historical_climateandThisRegion= NorthAmericaandThisCCode=GTM\# (last access: 29 November 2018), 2016. 